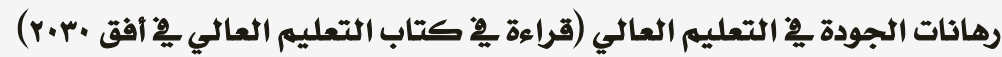

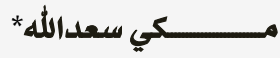 \\ جامعـة تبسـه، الجزائر

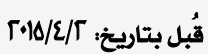

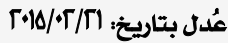

المستخلص: تحظى جودة التعليم العالي باهتمام كبير ِِّْمعم دول العالم، باعتبارها إحدى الركائز الأساسية لنموذج الإدارة الناجحة والتي يرتبط نجاحها ونجاعتها بالتتمية البشرية. وبناء على الرؤى المستقبلية، تسعى الدول المتقدمة إلى وضع استراتيجيات لضهمان الجودة وِ التعليم العالي، ومن المنظمات المستقلة والمهتمة بهذا الحقل منظمة التعاون والتتمية الاقتصادية (OCDE) وهي منظمة تضه ثثلاثين دولة من أقوى دول العالم وأغناها. أصدرت المنظمة يخٌ إطار اهتمامها بقضايا واستراتيجيات ضمان الجودة يِّ التعليم العالي، دراسة علمية

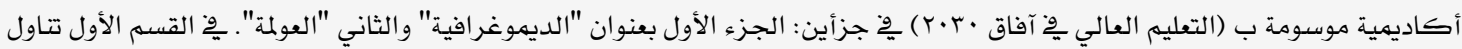
الباحثون تحديات النموالديموغرايو وانعكاسـاته سلبيا وإيجابيا على التعليم العالي. أما الجزء الثاني فخصص "للعولمة" وآثارها على فولى

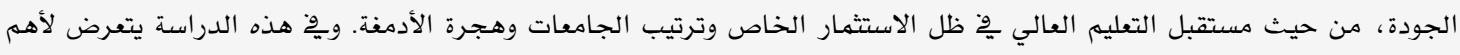

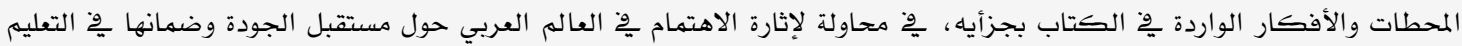

كلمات مفتاحية: ضمان الجودة، التعليم العالي، الديموغرافيا ، العولمة، منظمة OCDE.

\section{The Challenges of Quality in Higher Education: Reviewed Book of Higher Education on the Horizon of 2030, by OCDE}

Mekki Saadallah*

Tebessa University, Algeria

\begin{abstract}
Most of the developed countries in the world care about quality and the guarantee of education because it is considered as the basic pillars of the efficacious human development. In light of the basic transformations of the higher education, the organization for economic cooperation and development (OECD) has issued a book in two parts entitled "Higher Education in 2030". The first part treats the theme of "demography" and its impact on the future of the higher education in the context of two major indices; the aging of the European society and the growing of the ethnic diversity emerging from the regulated and illegal immigration. In the second part, the researchers expose the phenomenon of "Globalization", its manifestations and its effects on the higher education, especially those which are attached to private investments; to the establishment of the private universities; to the internationalization of the higher education and to its overtaking of the national and continental borders. The search presents the most important ideas and themes contained in the book for stimulating the interest about the future of the quality in the higher education and clarifying the approaches reached by the global research to improve the quality of training.
\end{abstract}

Keywords: Quality assurance, higher education, demography, globalisation, organisation.

*saadallah_58@yahoo.fr 
- اير لندا - أيسلندا - إسر ائيل - ايطاليا

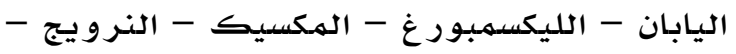

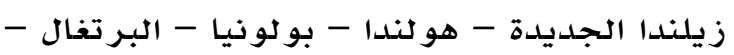

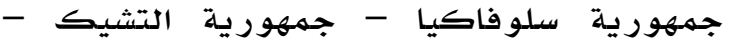

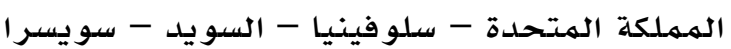

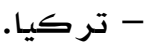

وتتعاون المنظمة مـع دول غير منتمية كالصين

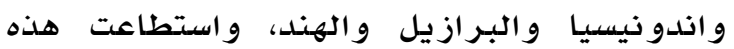

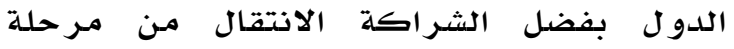
الاقتصاد المههم المستهلك و المكانة السياسية الثانوية إلى إدرالك درجة الاقتصداد الهنتج

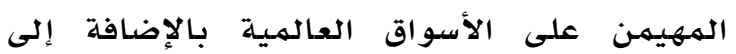
التأثير السياسي في القضايا العالهية. تجري اليوم مفاوضات جدية مـع دول الكتلة الشرقية قصد استقطابها والاستفادة مـن خبر اتها من خلال دعوتها إلى الانتهاء، وقد استجابت حكو مات كثيرة لهذه الدعوات.

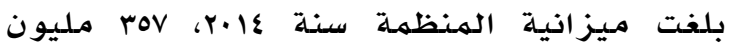

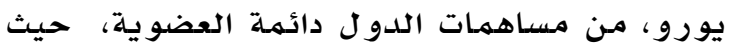
يتهم احتساب المساهمات الوطنية باستخدام صيغلة

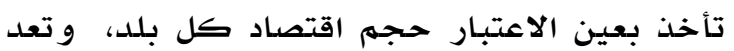

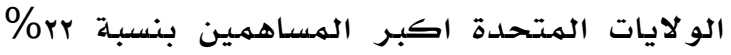

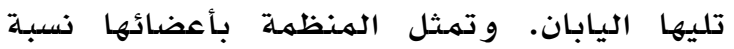
\% من المبادلات و الاستثمار ات الدولية.

تعالج الهنظمة من الناحية الأكاديمية أهم

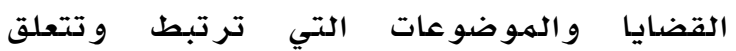
بتطوير الحياة الإقتصادية والإجتماعية بهدف

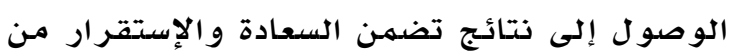
خلال تطوير برامـ الإستثمار المعرفي المـرتكز على راس المال البشري. و لتحقيق الغايات و الأهداف تمَّ إنشاء مجمهوعة مـن الهديريات تتكفل بانجاز دراسات ميدانية ونظرية موزعة كها يأتي:

ا. مديرية التعاون من اجل التنمية. r. مدير ية التبادل و الزراعة. r. مدير يـة القضايا الاقتصادية.
تدرك دول أوروبا الغربية وغيرها من دول

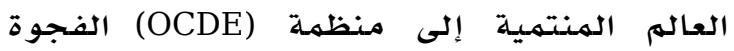

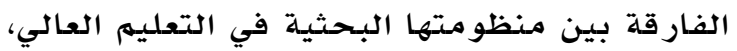
و تلك الهـسدة والهنجزة في الولايات المتحدة و واليابان و الصين.

تعود الإرهاصات الأولى لنشأة منظمة التعاون

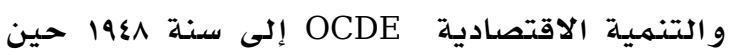
قررت مجرموعة من الدول، إنشاء تكتل اقتصادي

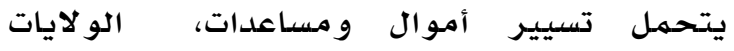
المتحدة الأمريكية من خلال مشرول مشروع مارشال الذي يهدف إلى إعادة (Marshall, 1880-1959)

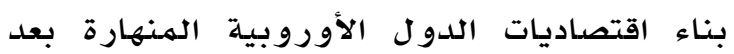

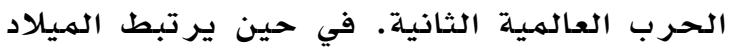

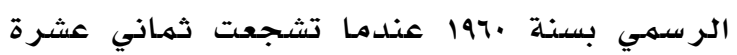
دولة (11) أوروبية على إنثاء منظمهة تكرس

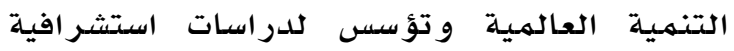
مستقبلية رائدة تكون أرضية لتطويه ولهير القارة الأوروبية و الخروج بها مـن نفق التخلف و آثار الحربين العالميتين.

و نظرا للفاعلية و المـردود العلهي والجاهزية في

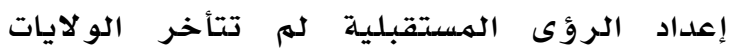

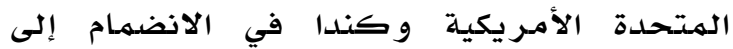

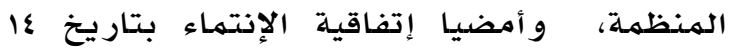

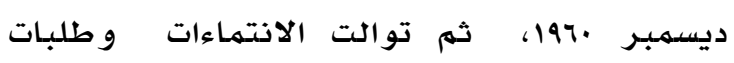

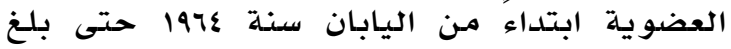

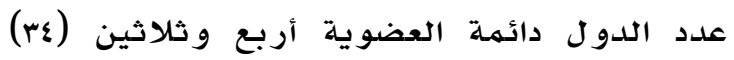
دولة، تسعى كلها للوصول إلى غاية جوهرية ترفعها المنظمة في ديباجتها، تحقيق الرفاهية إهية

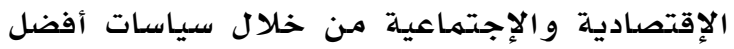
لحياة فاضللة.

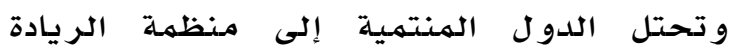
العالمية من حيث التطور الإقتصادي والإجتتماعي و السياسي. وهذه الدول هي: ألهانيا - استر اليا - النهسا -

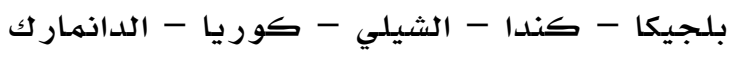

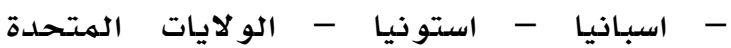
الأمريكية - فلنداه - فرنسا - اليونان - المـجر الوبان 
الأكاديمية لاعتمادها على إحصاءات دقيقة

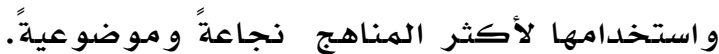

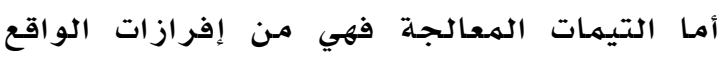

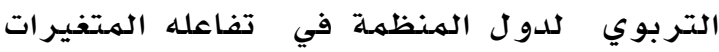

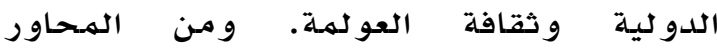

الهعرو ضلة للبحث و المعالجـة قضايا: إدارة أنظمة التعليهم المركبة.

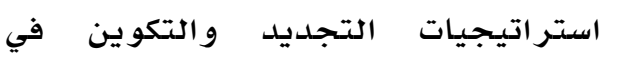
التعليهم. التربية و الرقي الاجتماعي.

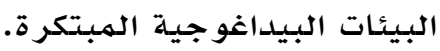

البيداغوجيا الجديدة والتعليهم الفعال.

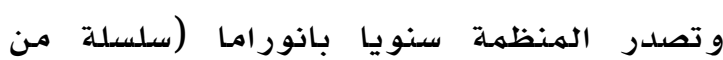

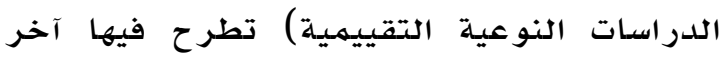
الأبحاث في حقل العمل التربوي ومات يتعلق

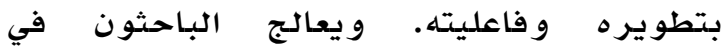

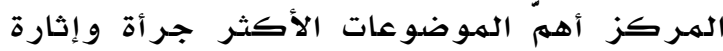
كقضايا التقويم وتعليم الكبار والتعليم الراقي،

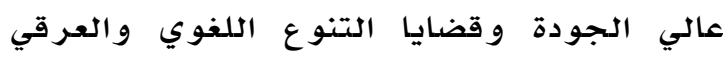

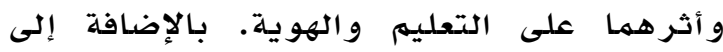

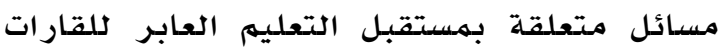
و مدرسـة الغد و مستقبل الجامعات في ظل ارتفاع النفقات.

وتفرع عن مديرية التعليم و الكفاءات مركز علهي مختص في البحث و والإبتكار التربوي، رسالته البحث عن الجديد والمبتكر. هو مركز

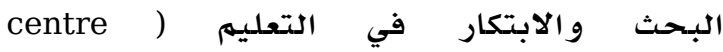
derecherche et d'innovation dans l'enseignement )

يرسم الهـر كز سياسات التعليهم في دول الهنظمة

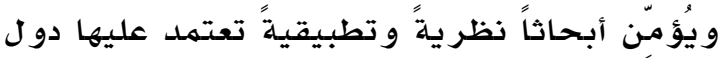

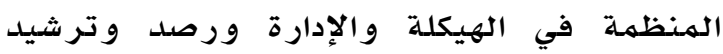
النفقات، يقول مدير المـركز (يجب أن يتجاوز

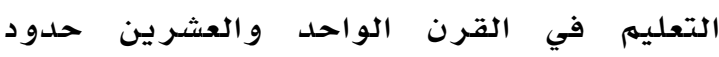
التوسِع الكمي، إلى الفعالية والإبداع والإبتـار ). و مـن انجازات المركز كتاب: التعليه العالي في

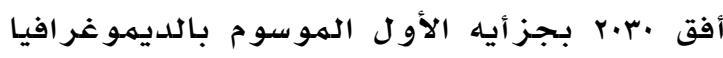

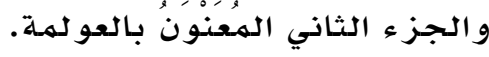

ع. مدير ية التربية و الكفاءات.

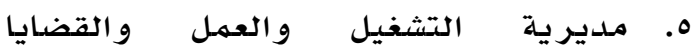
الإققتصسادية.

T. مركز ريادة الأعمال والشركات الصغيرة و المتتوسطة و التتهمية المحلية.

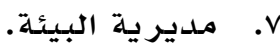
^. مدير يـة القضايا المالية و المؤسسات. 9. مركز السياسات و الإدارة الجبائية. ا. أ مدير يـة الإحصاء. 11. مديرية العلوم و التكنو لوجيا و الإبداع.

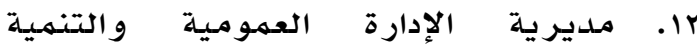
الإقليميلة.

يثير إنتباه الباحث أهمية كل المديريات

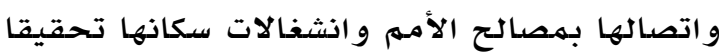

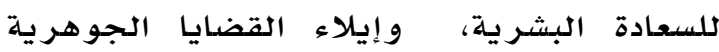

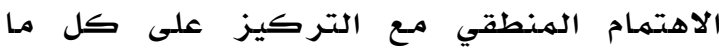

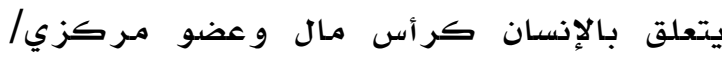

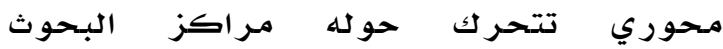
والدراسـات لتوفر له البيئة والفضاء المناسبين لحياة كر يمهة.

و من أهم مديريات المنظمة التي تتقاطع مـع

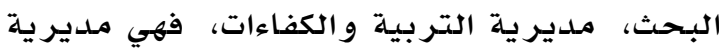

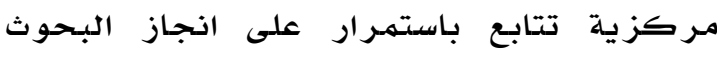

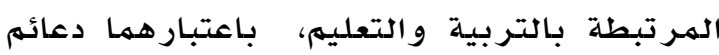
كل تنهية بشرية وكل تقدم تكنو لوجي.

و لأجل تكوين مجتمـع المعرفة ترهد المنظمة

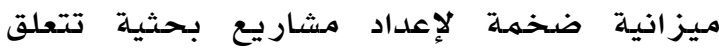

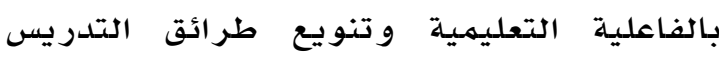

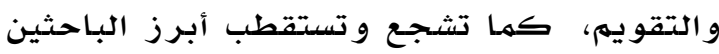
في الحقل التربوي لتقديم رؤاهم وتجاربهم

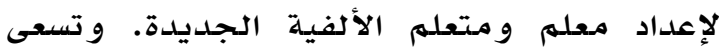

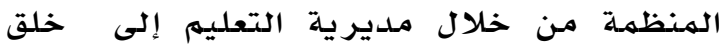

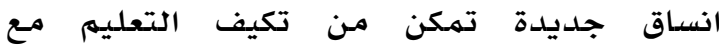

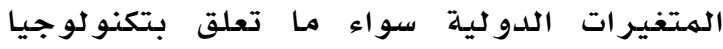

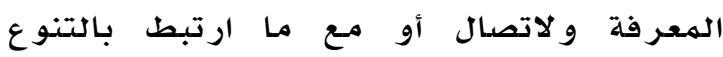
العرقي و الثقافي في زمن ولهد العولمـة. و تعد مكتبـة مديرية التعليهم والكفاءات من أثرى

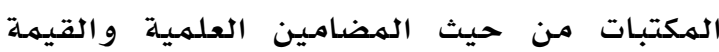


جامعة لافال Laval بكندا المنعقد في الفترة

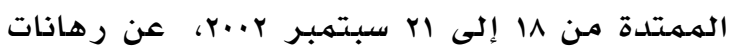

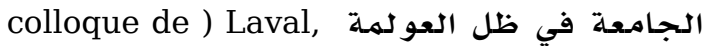

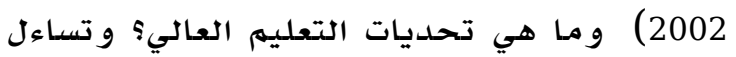

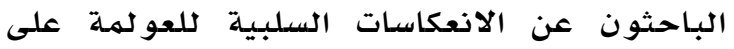

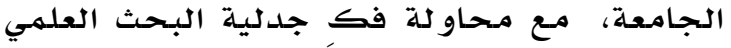
الأكاديمي في علاقاته مع الاستثمار التجاري

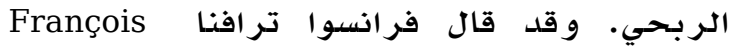
Travenas الكندية) "يجب على الجامعات أن تبقى وفية لجامعة لإل للقيم الأساسية المتمثلة في حركتي الأفكار

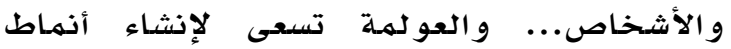
جديدة للتعاون بين جامعات الشمال والجنوب...

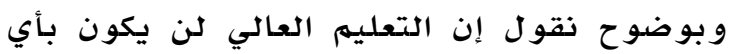
صفة سلعة أو بضاعة يجب أن تغطيها وترعاها اتفاقات الجات GATT و منظمة التجارة العالمية (Colloque de Laval, 2002) "OMC

أما البنك العالمي (2003) Banque mondiale,

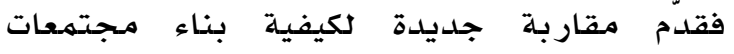

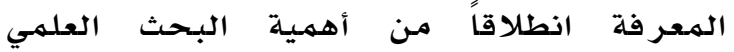

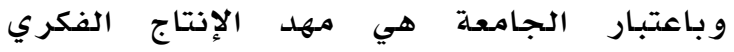
و الثقافي والعلمي، و وتساءل عن الفجوة الكبيرة بين الدول المتقدمة والنامية حول توفير التعليم

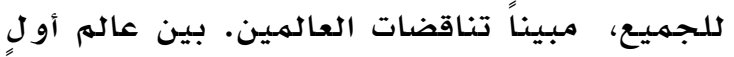
يعاني من عجز في رأس المال لتموين مشاريع

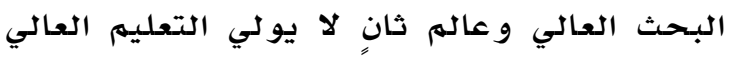
الأو لو ية الإستر اتيجية في سياساته.

أما منظمة التعاون والتنمية الاقتصادية (OCDE) فلم تكتف بالدراسات النظرية بل تجاوزت ذلك، الكاون فقد أنشأت مرصداً لتطوير التعليم العالي

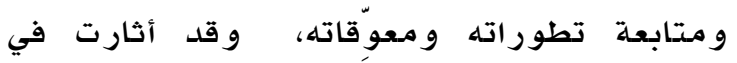
العديد من الدراسات قضايا جوهرية هامـة منها:

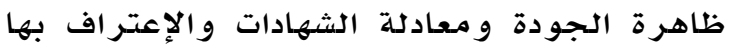

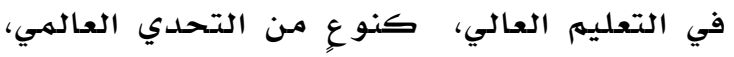
يجعل الدول تختلف في تقييم الشهادات التعليمية لاعتبارات في حالات كثيرة لا علاقة لها بالبحث الجامعي (OCDE, 2004).

و أثرت المنظمة (OCDE) رصيدها في إطار تطوير أنظمة التعليم العالي بإنشاء مركز
و نظراً لقوة التدفق المعرفي وزوال الحواجز

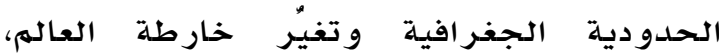
سارعت الدول الأورووبية الغربية إلى إعادة بناء

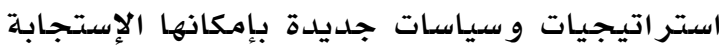

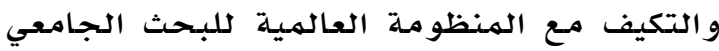

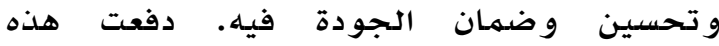
المؤثرات الكثير من الدول إلى مراجعة إنهة أنظمتها

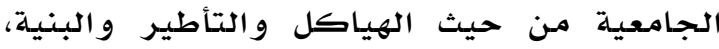

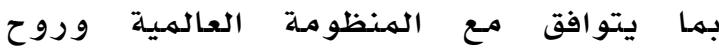
العولمة. فالجودة مصطلح مرتبط بمستوى الأداء

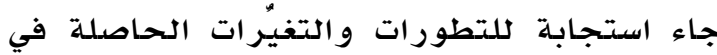

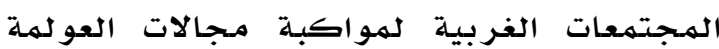

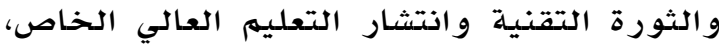

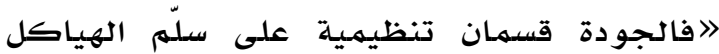

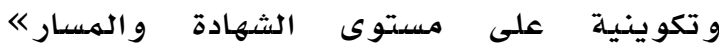
(Grainier, 2009)

ونظراً لارتباط الجامعة بالمجال العلمي و إنتاج المعرفة فهي في تلطور وحركية دائمة

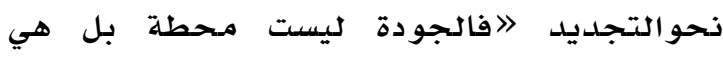
رحلة، هي مسار لا ينتهي. يكشف في كل محطة عن أوجه جديدة) (Perellon, 2003) أو فئة

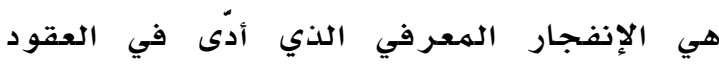
الأخيرة إلى فتح فجوات وثنرات في العي مختلف

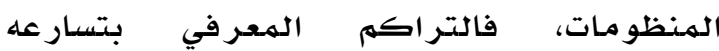
وسرعته لم تواكبه فتوحات في الأطر والمناهج

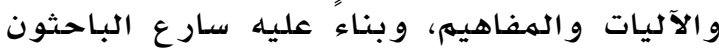
في حقول التعليم العالي إلى إعادة بناء منظومة ولئ فكرية ومفاهيمية جديدة لمفردات الجودة في

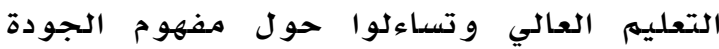
كفلسفة وثقافة و استر اتيجية لتحسين المنتج. وبهدف تجسيد الفلسفات والرؤى النظرية حول

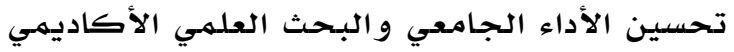

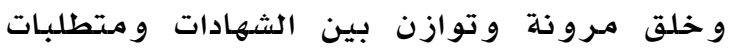

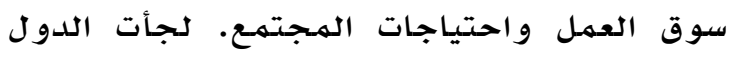

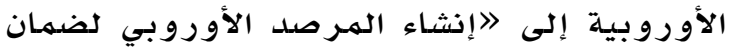

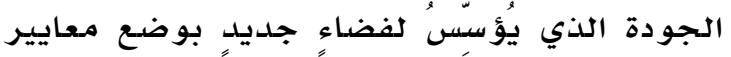
جديدة للتقييم والتقويم" (Darbellay, 2011). كما تعددت المؤتمر ات و الملتقيات حول التجديد في التعليم العالي، فتساءل الباحثون في ملتقى التى لهنيات 


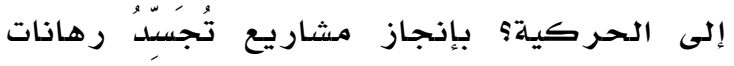
التعليهم العالي في العاله العربي.

\section{أهمية الدراسة}

ترقى هذه الدراسلة من حيث الأهمية إلى توضيح

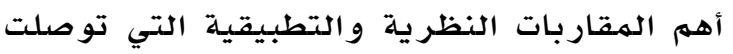

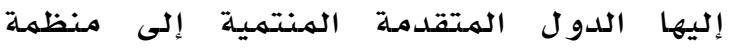
(OCDE)

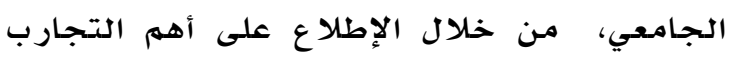

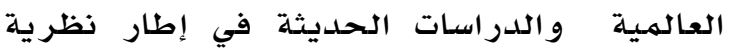

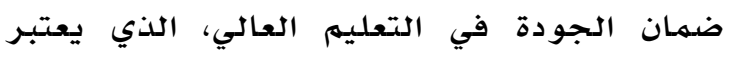
قاطرة التنمية و الإنتاجية.

إن تحسين الجودة وضمانها في التعليهم العالي

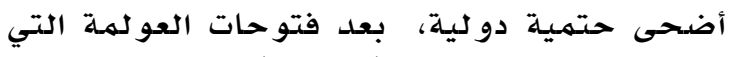

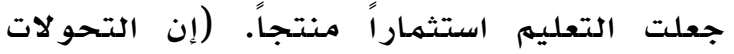

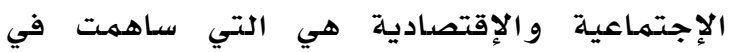
تثبيت خطاب الجودة) (Jean É., 2012).

و تكتسب الدر اسـة أهميتها من حيث أنها تجيب عن

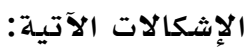

ا. ظاهرة شيـخوخة المهجتمع الأوروبي و انعكاسـات الظاهرة على التعليم العالي. r. الهجرة ورهانات التحاق أبناء الههاجرين بالتعليم العالي وتأثير ذلك ورهاب على البنية

الطلابية و الهوية و الخصوصية صية الثقافية.

r. التجديد في المهن الجامعية وتحديات القرن الواحد و العشر ين.

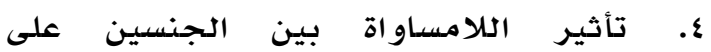
مستقبل التعليم العالي.

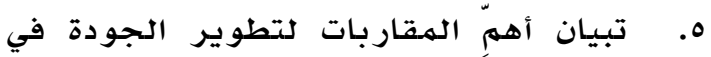
التعليم العالي وضرورة المعاريال توحيد المعايير

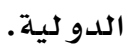

T. خلق آليات جديدة لتمويل وتغطية نفقات

$$
\text { التعليم العالي. التيات }
$$

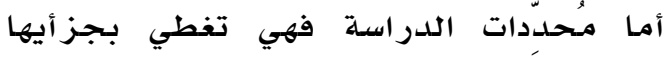

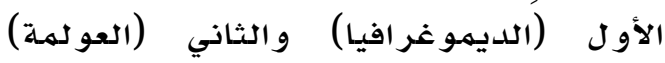
لمنطقة الدول المنتميـة إلى منظمهة (OCDE) ويغلب على هذه الدول القوة الإقتصادية

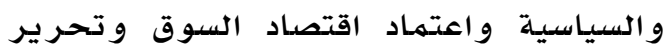

البحث و الإبتكار في التعليم (CERI) و الذي أصدر إلى غاية اليوم سلسلـة من الدراسـات الأكاديمية، منها ما يتعلق بالتعليهم الجامعي العالي وعلاقيه ماته ماته مـع التنمية المحلية والتي طرحت فيها المنظمهة مقاربات حول كيفيات استفادة المناطق الجهوية

من البحوث العلمية المنجزة في الجامعات (OCDE, 1999) المناطق الجهوية في إنتاج المعرفة وكيفية تصدير ها إلى العالم (OCDE, 2007) و في إطار

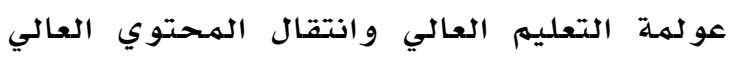

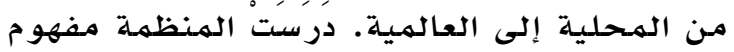

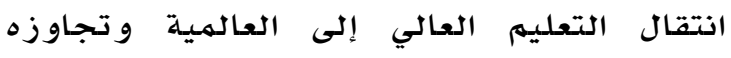

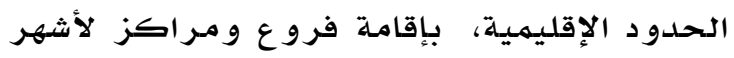

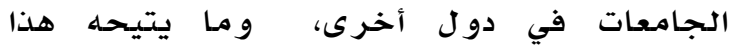

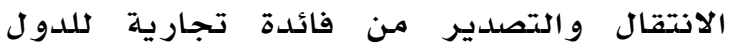

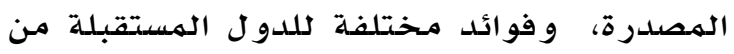
رفعٍ للمستوى وبعثٍ لروح المنافسة وغير ها من المنافع (OCDE, 2004).

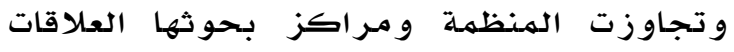

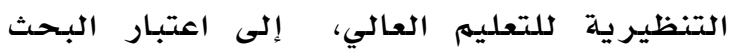
العلمي داعم للتنمية و آلية من آليات الإنتاج التي

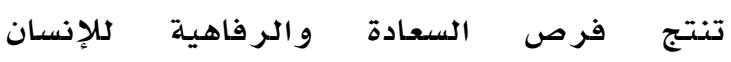
(OCDE, 2008)

كما دعت المنظمهة إلى ضرورة استخدام التكوين

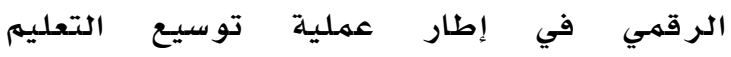

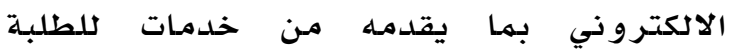
كاختصار المسافات و تقليص التكاليف و تنوع مصادر التوثيق (OCDE, 2005).

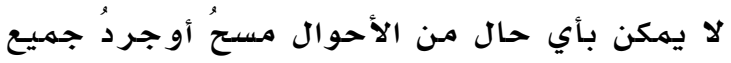

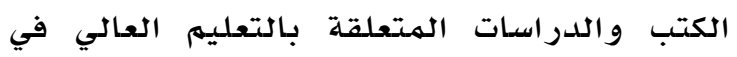
أوروبا، فبيبليوغر افيا التعليم العالي و وجودته

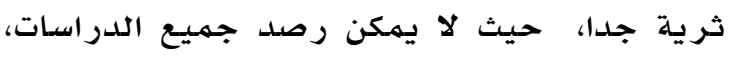
و قد اكتفى البحث بهسح وجرد دأهم الهقاربات الفرنسية لتطوير أنظمة التعليه العالي في دول

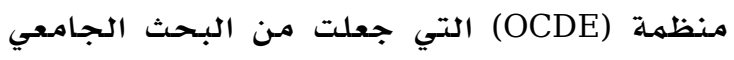

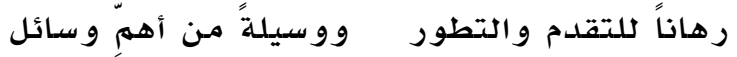
تحسين الظروف الهعيشية للهمواطن.

وتتسـاءل الدراسـة متى تتحول الهياكل العربية

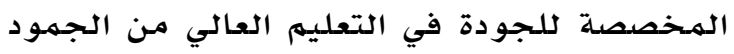


الهواليد. ويقابل هذا ظاهرة الهجرة بكل

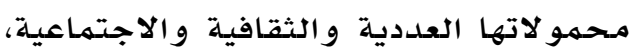
التي تنعكس على التركيبة الطلابية وهيئات التدريس و التأطير . قدمت الباحثة

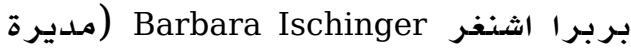

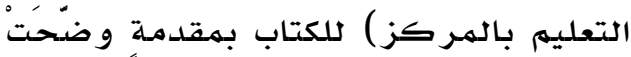
فيها رهانات و وتحديات مستقبل التعليم

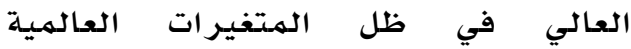
و الديمو غر افية.

r. في حين يقع الجزء الثاني الموسوم

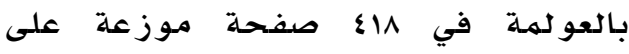

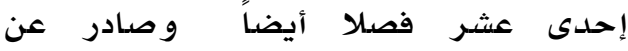

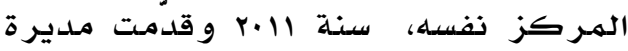

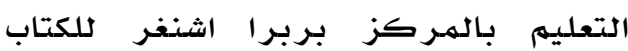
موضحة بعض الأفكار و القضايا ومنها أن

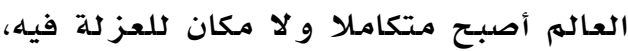

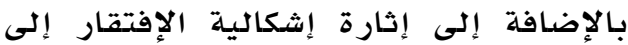

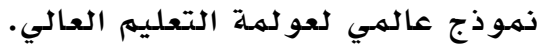

يعرض الباحثون في دراسـاتهم أهمَ الأنظمة

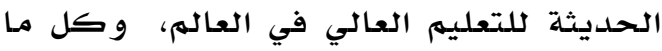

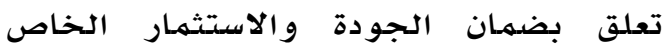
و التدو يل و غير ها.

انتهج الباحث في عرض الكتاب بقسميه الأول و الثاني المنهج الوصفي في مستح الهضامين

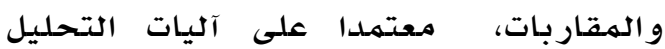
و النقد.

\section{الجزء الاول}

التعليهم العالي في أفق .ب.r، الجزء الأول الديمو غر افيا الميا

L'enseignement supérieur à l'horizon 2030, volume 1: démographie توزعت فصول الكتاب على المحاور الآتية: الفصل الأو ل:التوقعات الديمو غر افية على المدى

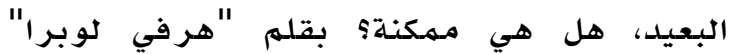
HERVE LE BRAS

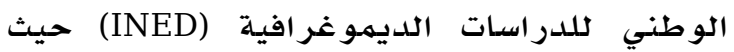
تساءل عن إمكانية و مصداقية التوقعات

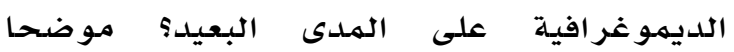

الهبادرات، و شعور ها و إيمانها بر هانات الجودة في التعليهم العالي و آليات تطويره، حيث تتنافس فيما بينها وتتطلع إلى أحدث

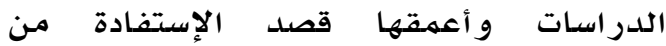
التجارب و الخبر ات، و تر صد ميزانيات ضدهمة

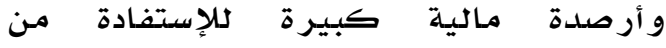

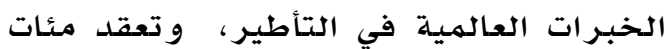

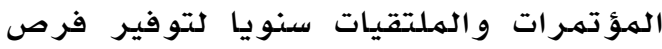

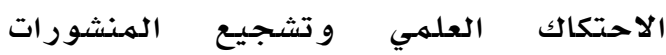
OCDE في دول منظمة (Beaucher, 2012) الإستتثمار في القيهم غير المادية، التي تشكل

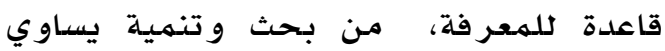

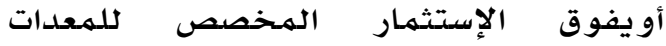
المادية 《) (Banquemondiale, 2003).

\section{منهج الدراسة}

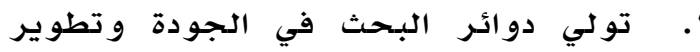

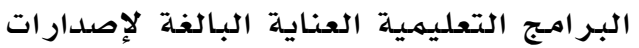

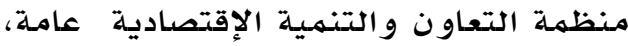

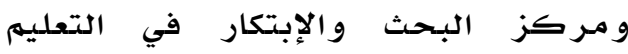
خاصدة. لارتباط حركة التعليم و التكوين

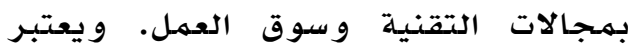
كتاب الجودة في التعليهم العالي في جزأيه الأول و الثاذي من أقوى الدرواسـات و أهمِهِّا

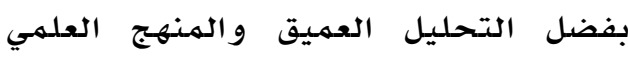
الأصيل الذي يعتمدد على أدق الإحصاءات

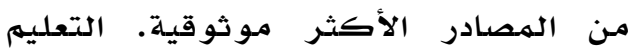

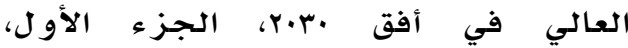

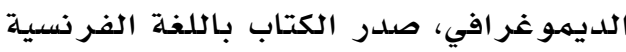

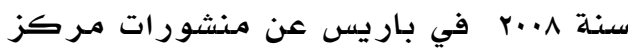

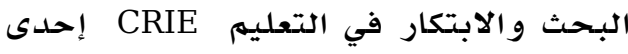

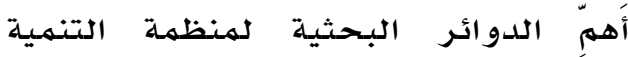
والتعاون الإقتصادية. يتوزع الكتاب على الكي

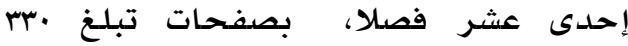
صفحة من الحجم المتوسط. تناول الكتاب في محوره الأساسي إثكالية التركيبة

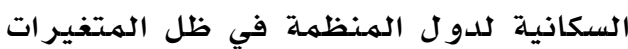
الدولية والإقليمية ومن أكبر التحديات

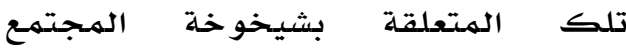

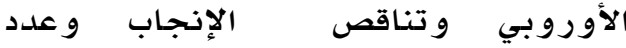


الهؤهلين وشيخوخة اليد العاملة المدربة، بمها ينذر بأزمة تأطيرٍ في المستقبل، و ويدعو إلى إنى

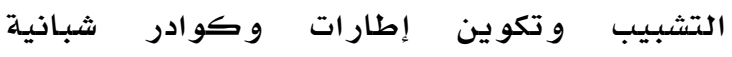
لتعويض النقص الذي سيحدث نتيجة التقاعد

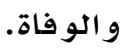

وأثار الكاتب أن معاناة دول المنظمة تكمن في

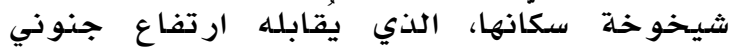

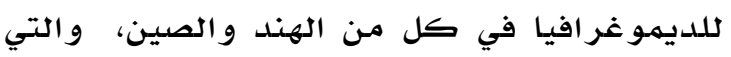

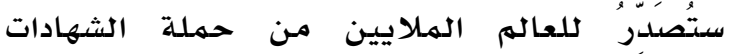
العليا.

الفصل الرابع تحدث فيه الباحثان يورغن اندارس (مركز دراسـات سياسـات التعليهم العالي لئيل جامعة تونتي، هو لندا (وركر (CHEPS)

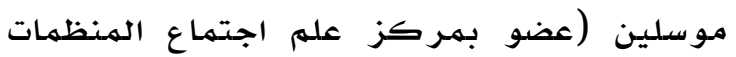

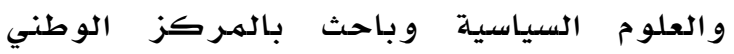
للبحث العلمي (CNRS) فرنسا). عن Jürgen Enders et Christine Musselin مستقبل المهن الجامعية، والمواقف التي ستكون

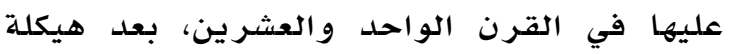

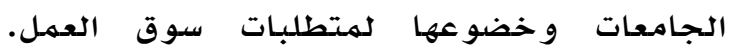
فإعادة الهيكلة تفرض إعادة في التكوين حتى التى

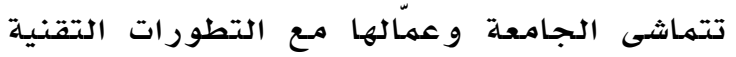

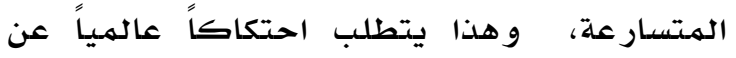
طريق الندوات و الملتقيات والمؤتمرات العلمئمية.

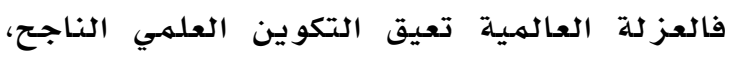
و لذلك يدعوالكاتب إلى ضرورة تفعيل التواصل

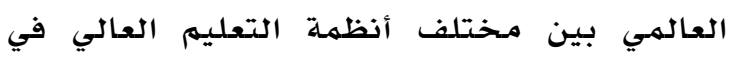
العالم. - 1المبمي

أما الفصل الخامس فقد تساءل فيه كل من ألريث تيخلر و صندرا بيرغ Ulrich Teichler et Sandra Bürger للبحث في التعليم العالي جامعة كاسيل kassel

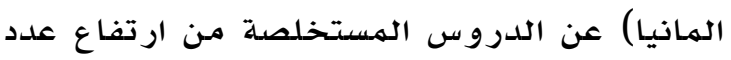

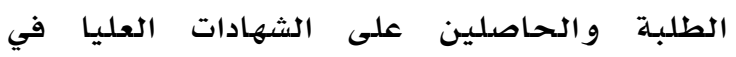

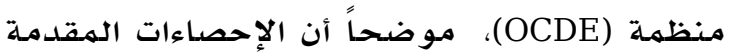

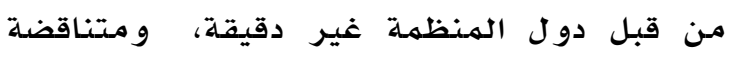
أحياناً و لا تعكس حقيقة عدد الطلبـة المنتسبين ولين

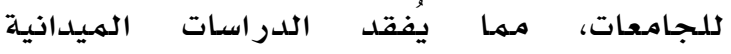

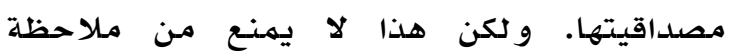

التناقضات بين نسب الإنجاب المرتفعة في الدول

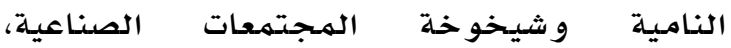

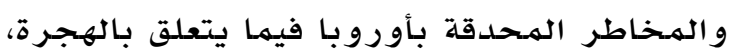
و ما يترتب على ذلك من ارتفاع عدد الطلبة الأجانب في الجامعات.

كما تناول الكاتب المتغيرات الدولية والتي والتي

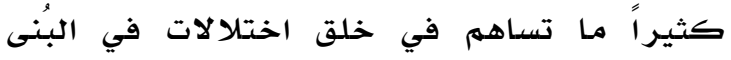

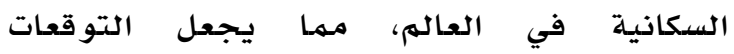

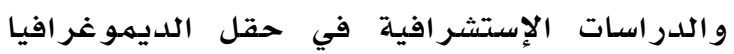

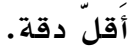

الفصل الثاني مـن الكتاب أثار فيه الباحث في

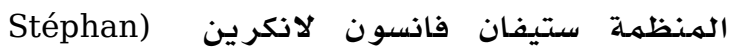
فن مركز البحث و التجديد

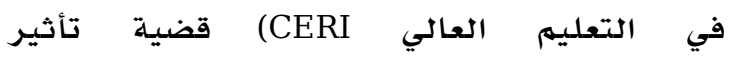

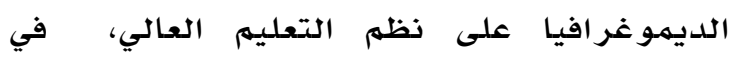

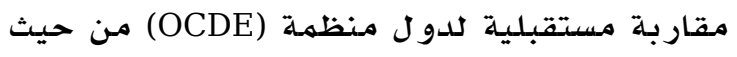

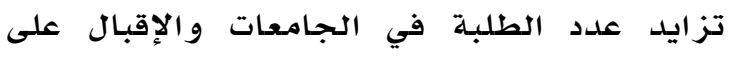

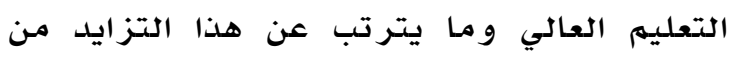

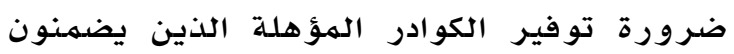

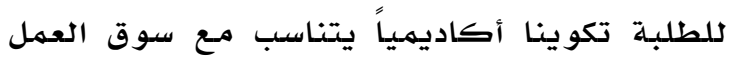
الدو لية و متطلبات الإنتاجية. وختتم الباحث مقالده

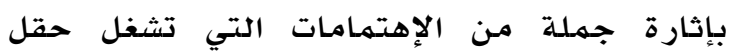

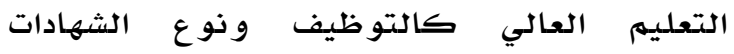

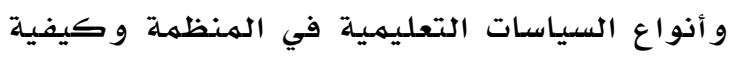

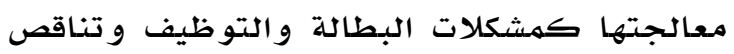
عدد الطلبـة والتنافس العالهي في حقل التكوين

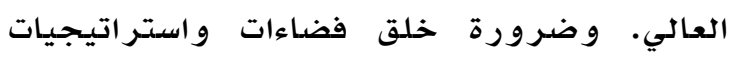

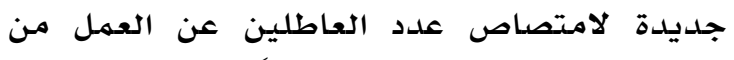
حملة الشهادات العليا. مضيفاً على أن الن النمو النول

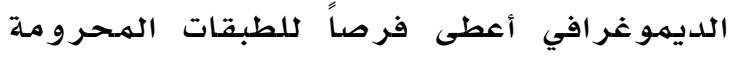
و المنحدرة من أوساط اجتماعية ضعيفة وفقيرة للوصول إلى مـر اتب عليا في التعليهم العالي.

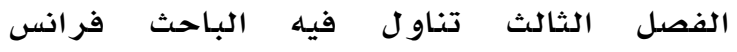

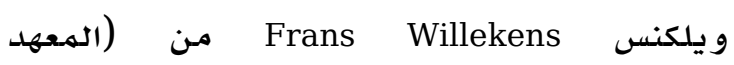

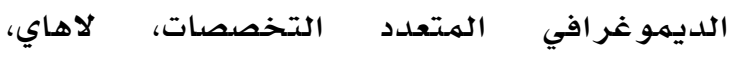
هو لندا (NIDi) تأثير اتجاهات النـمو الديمو غر افي في منظمهة (OCDE) من حيث شيخوخة العها العمال

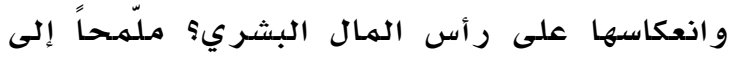
أن سكان المنظمة يعانون مـن تقدم سنّ العها العمال 
وظاهرة انخفاض عدد الطلبـة في كل من اليابان

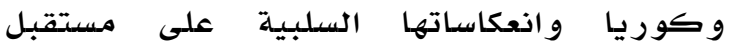
التعليهم العالي موضحاً أنذه رغم التطور التهار الكبير

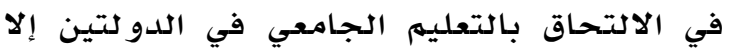

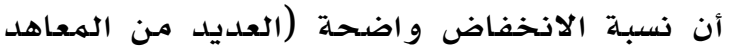
الجامعية في عجز عن استقطاب العدد الكافي من

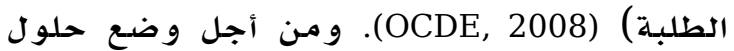
للمشاكل الجامعية لجأت الدولتان إلى وضع إنع

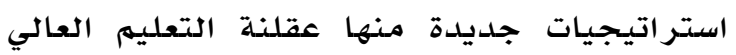
من حيث التكاليف والجودة بالإضدافة إلى تشجيع التنمية الجهوية قصد خلق توازنات بين المدن

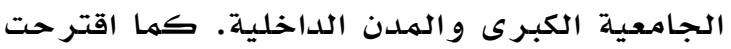
الحكو متان إنشاء مراكز لتتههين الدائم التي

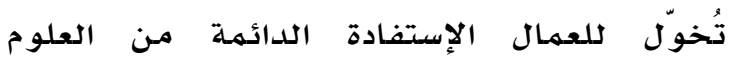
و التقنيات و التحكم في آليات الإنتاج الحديثة.

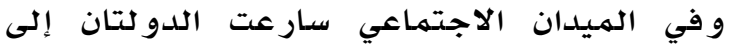

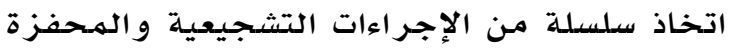

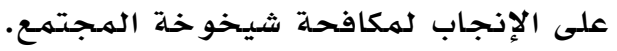

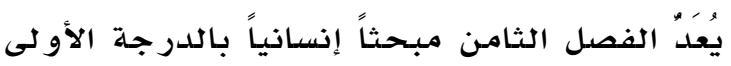

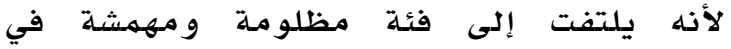

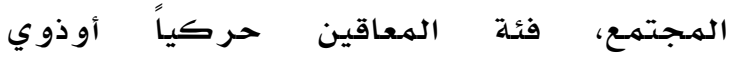
الاحتياجات الخاصة بمختلف و أثكال إعاقاتهم.

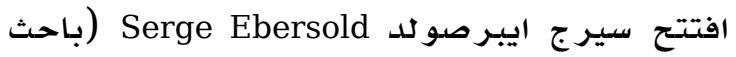

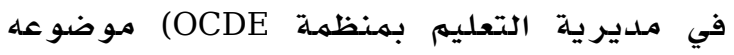
بر صد التطورات التي وصل إليها التعليم

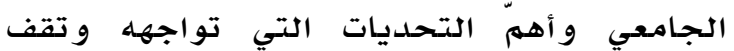
عائقا أمام اتساعه لتغطية طبقات اجتمهاعية مختلفة، ومن هذه الفئات طبقة المعاقين قائلا

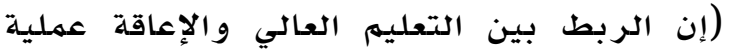
ليست متناقضة) (OCDE, 2008) و لاحظ أن نسبة النائ

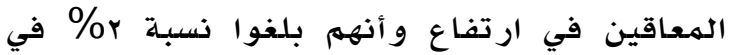
بريطانيا سنـة 1990 من عدد الطلبة الجامعيين، و أن العدد في تزايد (يقدم الباحث إحصاءات رسمية حول عدد المعاقين في التعليم العالي في

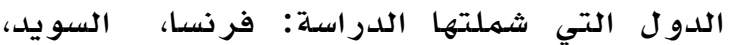

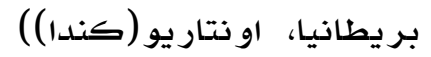

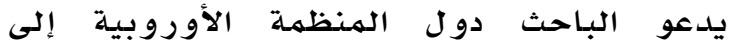

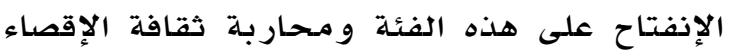
والتهميش مـع اتخاذ سياسـات جديدة منها اقتنـاء
ارتفاع أعداد الطلبة في التعليم العالي وتحصلههم

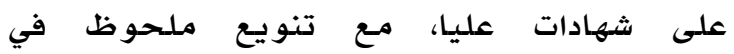
التخصصات وارتفاع طفيف في التخصص اتخصات المتعلقة بسوق الإنتاجية، ومتطلبات المؤسسات الصناعية و الإقتصدادية.

في مقارنته للإحصداءات المقدمة مـع بقية دول

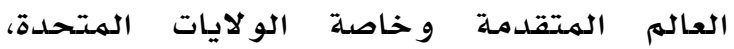
لاحظ الباحث أن الفجوة ما زالت كبيرة. داعياً دول المنظمة إلى تعديل سياسـات التعليم العالي

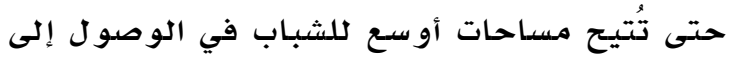

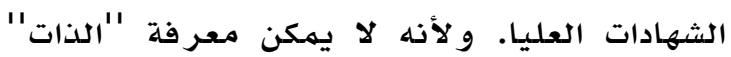

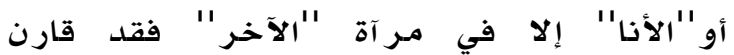

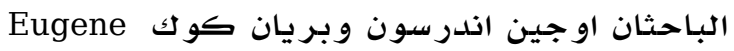
Anderson et Bryan Cook جامعة ميامي، الولايات المتحدة، متخصص في إدارة الأعمال) في الفصل السادس بين النواليات النظامين التعليميين الأوروبي و الأمر يكي في مقالهما حول

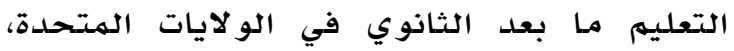

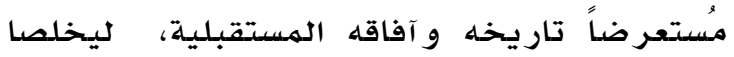
إلى أن التعليم الجامعي الأمريكي في ارتفاع

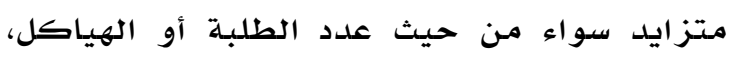

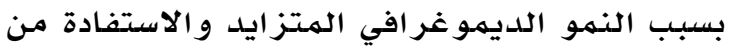

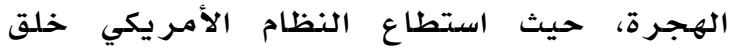
مناخات للتأقلهم و التكيف بسبب سياسـة المواطنـة و التجنيس. فاستقطب النظام الجامعي الطاقات

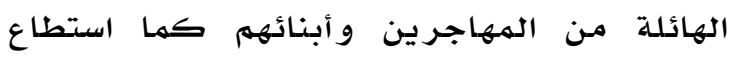

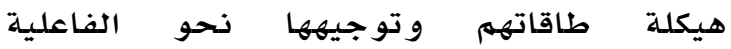

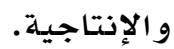

و لاحظ الباحثان اهتهام السلطات بالتعليهم العالي

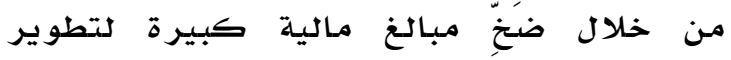

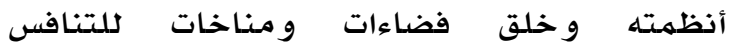

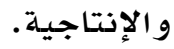

طرح الكاتبان تيري كيهم (باحث من جامعة برونيل وومركز البحث والتجديد في التعليم

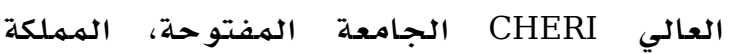

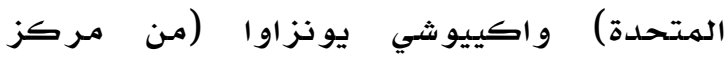

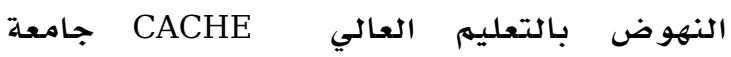
توهوكو، اليابان (Akiyoshi Yonezawa et Terri

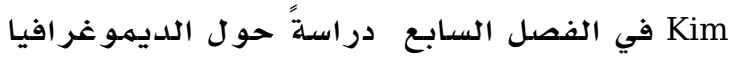


كماً و وكيفاً، وعاً و عدداً. سواء فيما تعلق بالوصول إلى التعليه العالي أوفي الحصول على

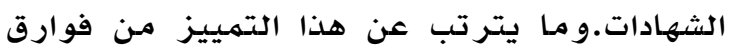

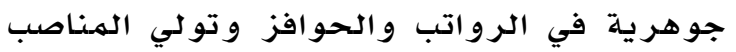
و المسؤوليات. وقد لاحظ الباحث سيطرة الإناث

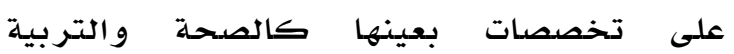
ويقابلها سيطرة الذكور على الهندسة و الزراعة.

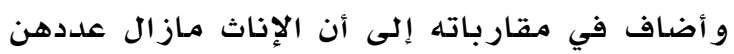

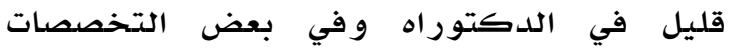

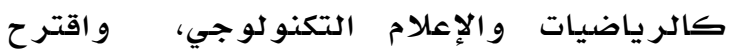
كإجراءات عملية محاربة النمطية التي تجعل الجنسين رهينين لتخصصات بعينها ودعا إلى تطوير المجتمعات لأن التكامل يصنعـه الجنسـان. الجزء الثاني

التعليم العالي في أفق .r.r الجزء الثاني:

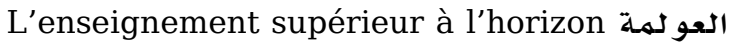
2030 volume 2: mondialisation

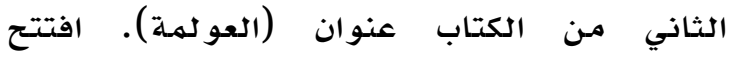

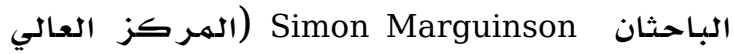
للدراسـات التربوية، جامعة ميلبورن) و Marijk van Der Wende بجامعتي توينتي TWENTE و جامعة أمستر دام) الفصل الأول من الكتاب بدراسـة مفصلة حول

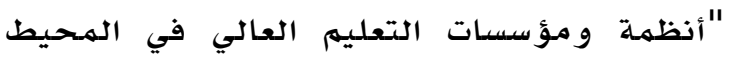

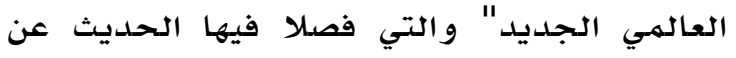
الفروق بين مصطلحي العول لمسة و العالمية، مؤكدين على أن العالهية مفهوم إرادي يعتمدد

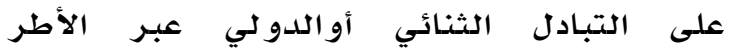

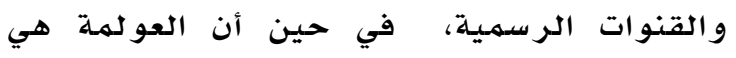

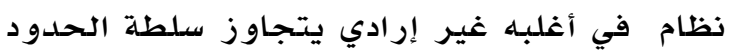
ليفرض أنهاطه و آلياته الخاصة و والتي تكون قصر ية في أغلبها.

و أثار الباحثان إلى أن مؤسسات التعليم العالي

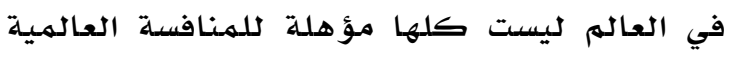

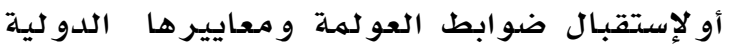

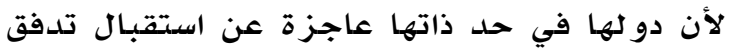
العولمة من حيث سرعة المعلومة ملة و كثافتها. ويفرّ الباحثان بين مفهومي العولمة و الأمـركة

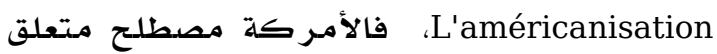

التجهيزات الخاصدة وتشريع قوانين لحماية هذه

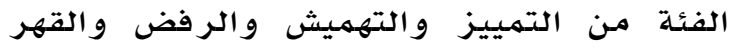

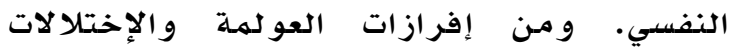

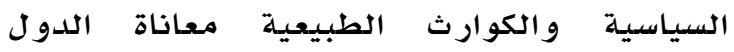

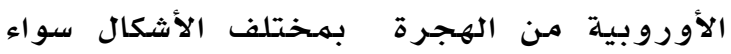

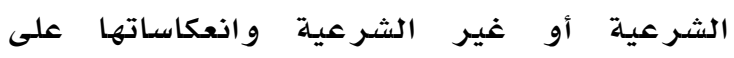

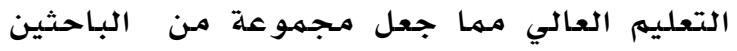
يتساءلون في الفصل التاسـع حول إمكانية وصدول الههاجرين أو أبنائهم إلى التعليهم العالي. اختار

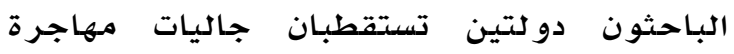

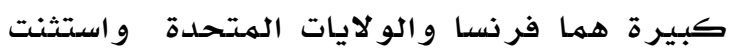
الدراسـة الطلبة الأجانب (البعثات الطلابية) لأن فئن

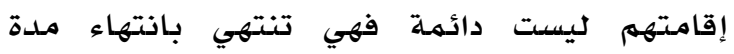

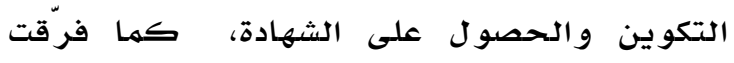

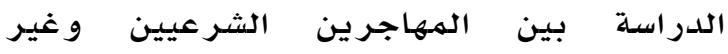

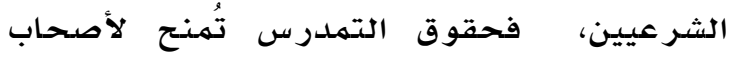
الوضعيات القانونية دون غيرهم من المتواجدين المهرفين على تراب دولة بطريقة غير قانونية.

لاحظ الباحثان فر انسيسكو مار موليجو Francisco Marmolejo Sean Manley-Casimir

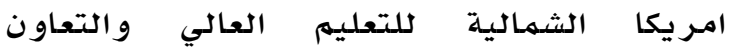
غياب إحصاءات دقيقة حول هوية (CONAHEC)

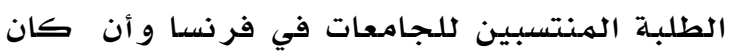
عدد أبناء السكان الأصليين يفوق عدد نظرائهم

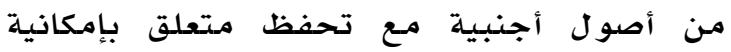

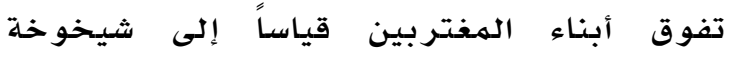

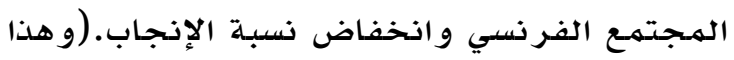

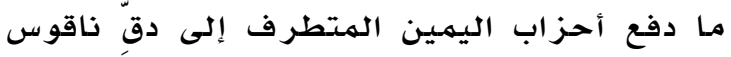

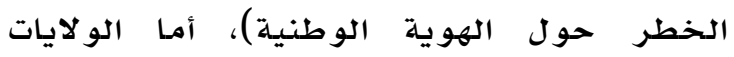

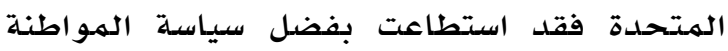

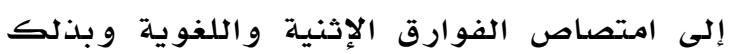

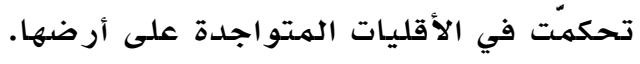
دعا البحث في خاتمته إلى ضرورة عقلنة التعليه العالي وخلق توازنات بين السكان الأصليين

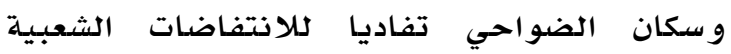

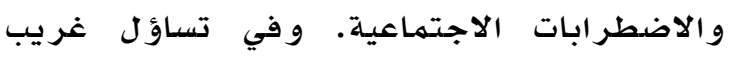
و مثير يستنهض الباحث ستيفان فانسون لانكران Stéphan Vincent-Lancrin منظمة OCDE إلى ظاهرة الفوارق بين الجنسين 
و الذي تسهم فيه آليات غير تقليدية، فهو ضرب

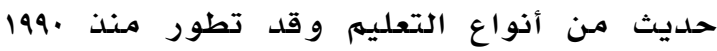
حيث تزايد عدد الطلبة الراغبين في الدراسـة في

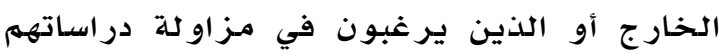

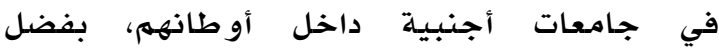
الترتيب العالمي لهذه الجامعات و اتخاذ معايير

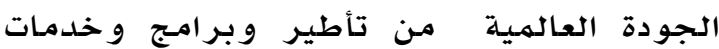
بحثية وتوظيف للتقنيات المعاصرة في البحث

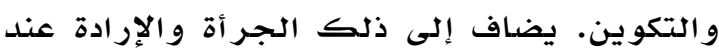
الكثير من الدول التي أرادت أن تطور نفسها عن

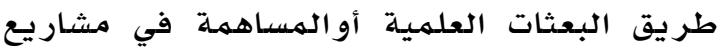
البحث و التبـادل العلمـي و الثقافي.

يشير الباحث إلى أن الدول المنتمية إلى منظمة (OCDE) الطلبة بين بلدانها (يحدد الكاتب ببيانات دقيقة تعداد الطلبة في كل دول المنظمة، صفحات برئ . ( 17

وبفضل التعليم العالهي أصبح بإمكان الطلبة

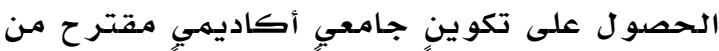
طرف جامعة أجنبية دون مغادرة أوطانهم و ذلك

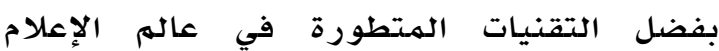
و الإتصال وبمساهمـة فعلية وجادة من قبل الطلبـة

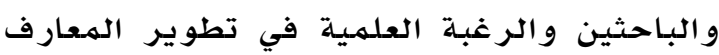

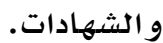

يُنوّه الكاتب في نهاية مقاله إلى أن دول الهـظمهة

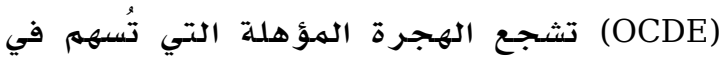
تطوير البحث العلمي، كما تتبادل المعلومات الهـره

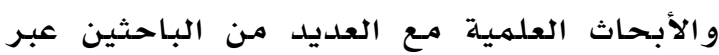

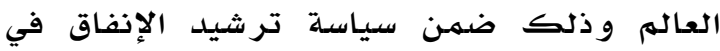
البحث.

في الفصل الثالث يذهب الباحثان الأستراليان

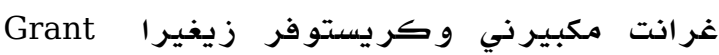
McBurnie et Christopher Ziguras بالهعهد الملكي للتكنولوجيا بملبورن) إلى إثارة

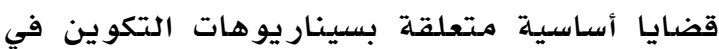
المؤسسات العالميلة من ميث نوع التكوين

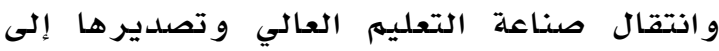

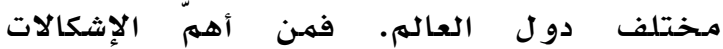
المطروحة في ضوء منظومة تصدير التعليهم
بالنظام الأمـريكي وسياسته في تطوير التعليم

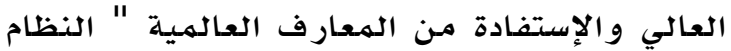
الأمريكي أكبر مستفيد من هجرة الأدمغة....مـع

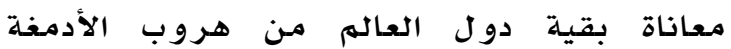

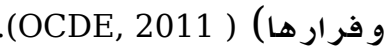
ويخلص الباحثان إلى النتائج الآتية: - -

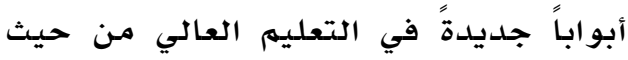

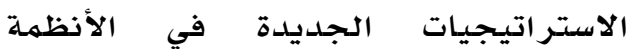

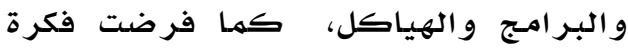

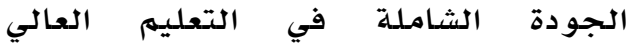

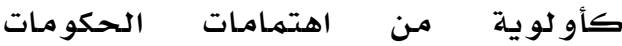
و الهنظمات ومـراكز البحوث.

أسهمت العولمة لأول مـرة في خلق شبكة عالمية للتعليهم العالي يتبادل من خلالده

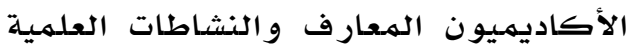
و البر امـج التر بوية و الخبـر ات الخـاصدة. جاءت العولمة بفكرة التعليم العالي

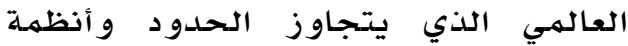

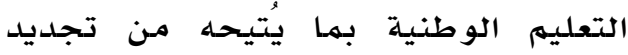

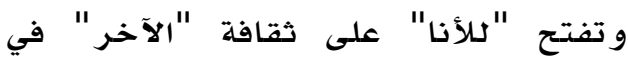

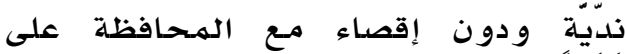
الهوية و الخصوصية ودون إنيات الثقافية. وختم الباحثان موضو عهما بإثارة إثكالية

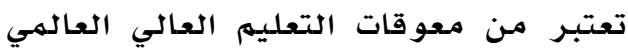

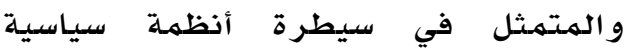

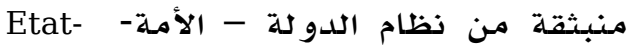
Nation بالقيم الوطنية مـما يحول دون التفتح

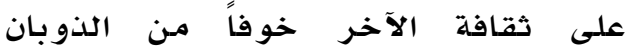
و الإنسلاخ و التماهي مـع ثقافة الآخر . من الفصول الهامـة والجوهرية للكتاب الفصل الثاني الموسوم ب "التعليهم العالي: إتجاهات و آفاق المستقبل" بقلم الباحث ستيفان فانسون لانكين Stephan Vincent-Lancrin (باحث في في مـركز البحوث والتجديد في التعليه (CERI) حيث يرصد الكاتب جملة من الملاحظات حول التعليم العالي العالهي العابر للحددود الوطنية 
يحاول الباحث في مقاربته الوصول إلى نموذج

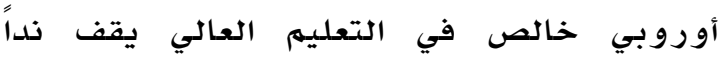

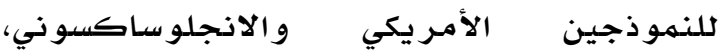

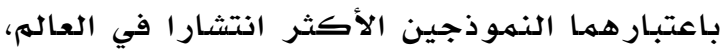
و الأكثر محاكاةً و تقليداً.

ير صد الكاتب المبادرات الأوروبية الساعية إلى ألى

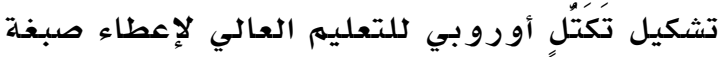
وهوية للجامعة الأوروبية ويرى لونى أن مسار

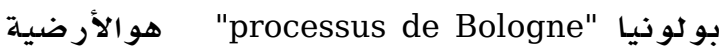

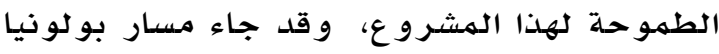

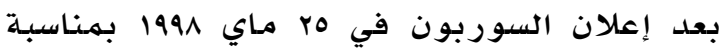

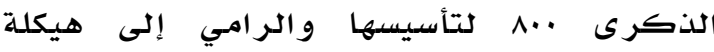
النظام الأوروبي للتعليم العادي. جاء مسار بولونيا في 19 جوان 1999 و الذي ضهَ”

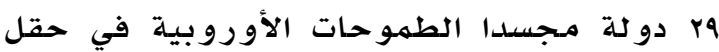

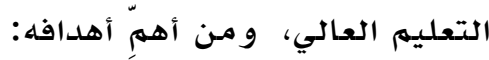

اعتهـاد نظام أوروبي للشهادات وتوحيد

معايير معادلتها.

إنشاء مسار جامعي موحد يعتمدد على مانى

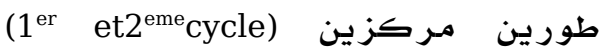
وطور ثالث للبحث (3 $3{ }^{\mathrm{eme}}$ cycle)

تطبيق نظام الائتمان "les crédits" في تقييم أعمال و انجازات الطلبية الطمان ترقية وتشجيع انتقال الطلبـة والأسـاتذة و البـاحثين.

وضع أدوات و آليات مشتركة كتقييم أفضل لجودة التعليه

Stratégie de Lisbonne أما إستر اتيجية لشبونة

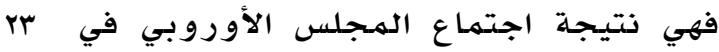

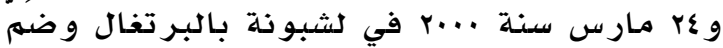

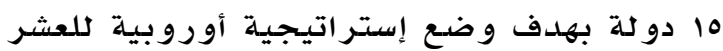

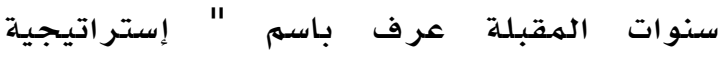
لشبونة " وون أهمِّ أهدافه تهيئة الإنتقال من الهن

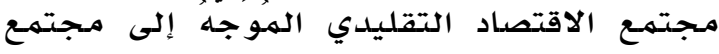

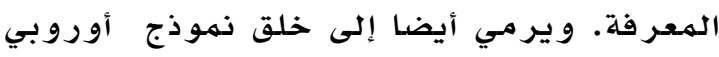

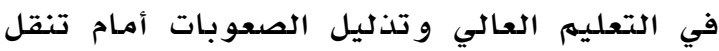
الطلبة و الباحثين.

ومن صعوبات تطوير التعليم العالي الأوروبي صعوبـة المسنافسـة مـع أمـريكا، فقد أثـار تقرير لـرير
العالي معادلة الشهادات الوطنية والأجنبية والشهادات الأوروبية المهمنوحة في دول أخرى الهى مـع مثيلاتها في الدو لة الأم أو الأصلية. يذهب الباحثان إلى أن تكاليف التعليم العالي

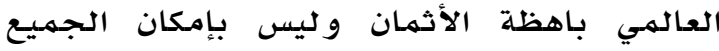

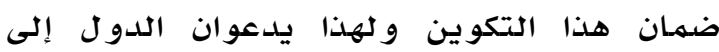
تخفيف الأسعار و التكاليف والسعي في المـر احل الأو لى إلى اعتماد سياسة التعاون ثم التدر ج في

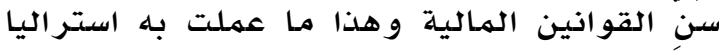

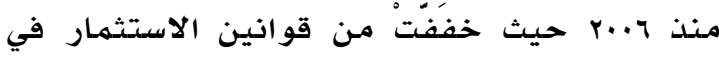

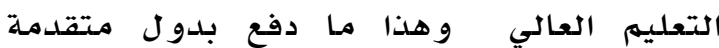

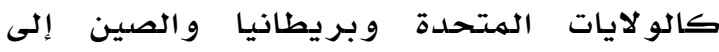
تقليدها في وضع تشريعات و نصوص قانونية

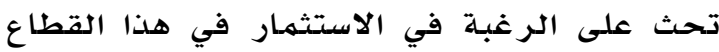
الحيوي.

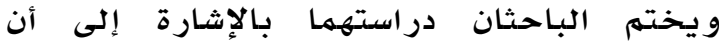

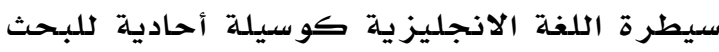
و المعرفة بإمكانه عرقلة الاستثمار في التعليهم العالي، لأن الطلب عليه كبير من دول دالهر الشرق

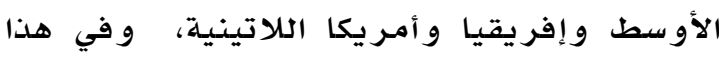
دعوة صريحة إلى الإنفتاح على اللغات الأخرى ولى ولى ولى كالعر بية و الفر نسية و الإسبـانية.

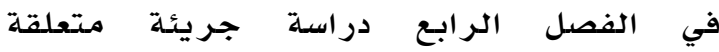

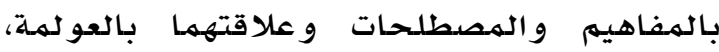

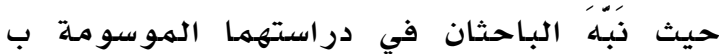

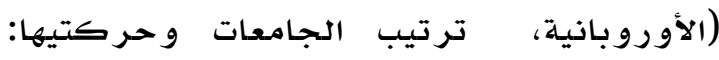

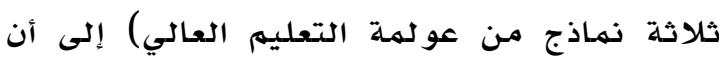
ظاهرة أوروبانية التعليهم العالي سياسـة فرضتها

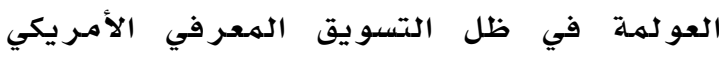

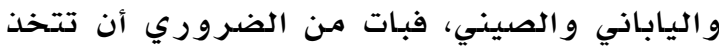

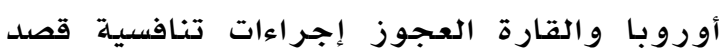
التقليل من حجم النفوذ الأمريكي في ميداء إدوان التعليه العالي، و ولكن الاستجابة الأوروبية متباينة من دولة إلى أخرى (OCDE, 2011)

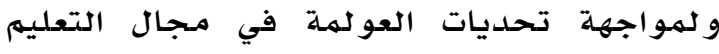

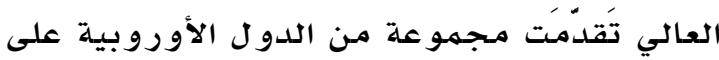
رأسها بريطانيا وفرنسا وألمانيا في سنـة 1991 إلى اقتراح مشروع أوروبي لتطابق الشهادات و معادلتها في أوروبا. 
البحوث و الدراسات و الهنشورات العلمية بشكل كبير) (OCDE, 2011) الإرتفاع في عدد البحوث

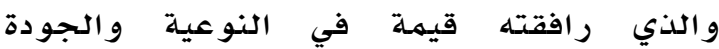
و الفاعلية يعود إلى دخول القطاع الخاص في لئي

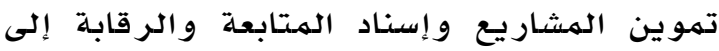
هيئات مؤهلة و متخصصئ (OCDE, 2011). أما في مجال براءات الاختراع فيلاحظ الباحث

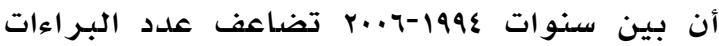
في الولايات المتحدة الأمريكية وتجاوز الثيدات الثلاثة أضعاف في دول منظمة مئ OCDE) (OCDE, 2011). و في نظرة إستشر افية يرى الباحث أن آفاق

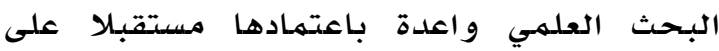
الشراكة الدولية والتموين الخارجي و الخاص مع ارتفاع عدد الطلبة والباحثين. وسوف يرتكز

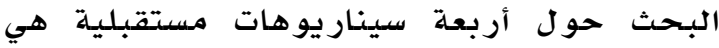

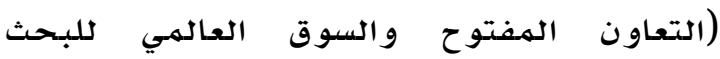

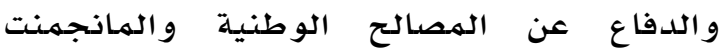
العمو مي الجديد) (OCDE, 2011).

و يختم الكاتب بقوله أن هذه السيناريوهات ليست قراءة للمستقبل و لا تقديم لمستقبل مثالي و لكن

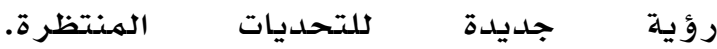

.(OCDE, 2011)

حول فكرة استيقاظ العمالقة يرى الباحث

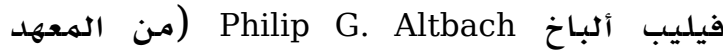

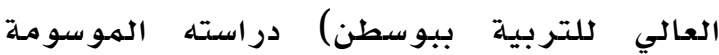
"أنظمة التعليم العالي الصينية والهندية، اليوم

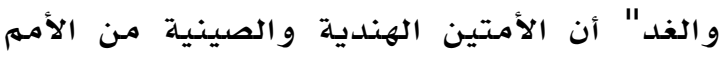

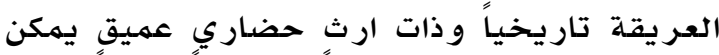
استثماره في أي طور و ميدان وبالتالي فهما مـن

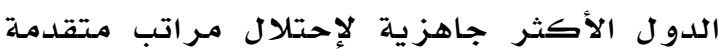

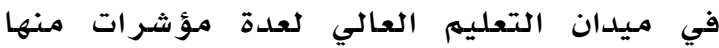
الإرتفاع الكبير في عدد الطلبة الهنتسبين

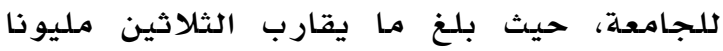

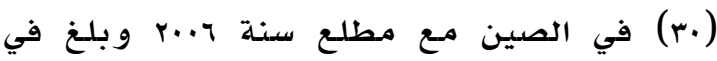

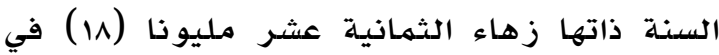

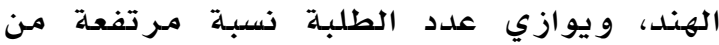
الأسـاتذة والباحثين يتوزعون على مختلف دوان لهول العالم ويحتلون مناصب مرموقة في مراكز

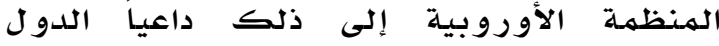
الأوروبية إلى تحرير المبادرات وتشجيع التتقال الطلبة داخل الدول الأوروبية وتوفير منحٍ

دراسية لطلبة الدول المتخلفة (OCDE, 2011). في ختام الدراسلة أشار الباحثان إلى ظاهرة

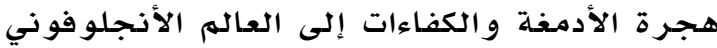

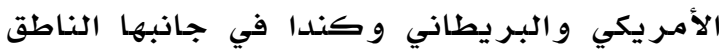

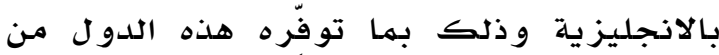

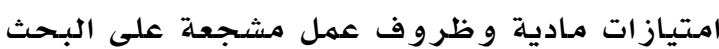

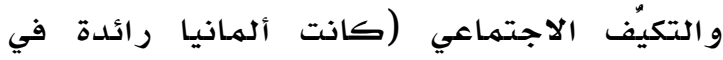
استقطاب الأساتذة وطلبة الدكتوراه الأجـانب،

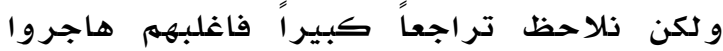
الآن إلى أمريكا وبر يطانيا) (OCDE, 2011).

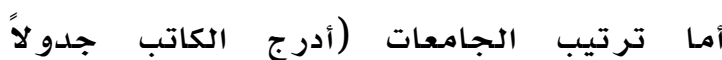

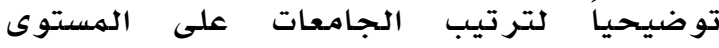

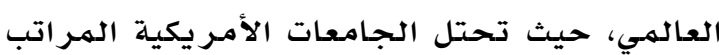

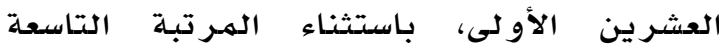

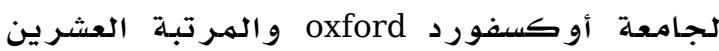
لجامعة طوكيو (تصنيف شنغهاي V...V).

وحول سيطرة الجامعات الأمريكية، يشير الباحثان إلى ضرورة إعادة النظمر في معائير

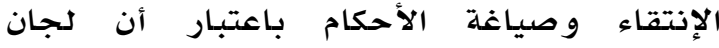

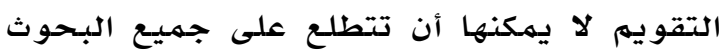

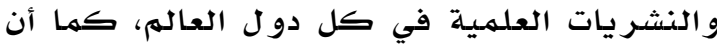
بعض الأحكام تتدخل فيها معايير أخرى، شأنها شأن جائزة نوبل التي تتدخل فيها المصالح السياسية .(OCDE, 2011). تونسان.

Stéphan ي الفصل الرابع ينقلنا الباحث Vincent-Lancrin التعليهم الجامعي والهتمثل في نوعية الأبحاث

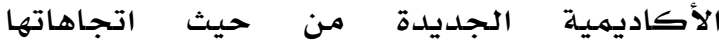

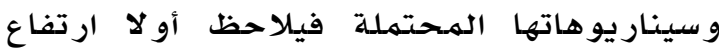
حجم الإنفاق على البحث العلمي في دول منظمهة بغرض تحسين الوضـع المعيشي للإِنسان (OCDE)

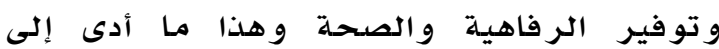
ارتفاع نسبـة العاملين في قطاع التعليهم العالي

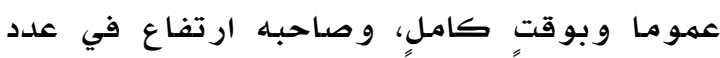
الباحثين الدائمين و المساعدين مـع تفاوت بسيط

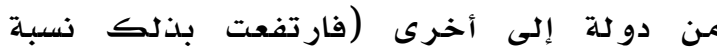


التدرج والعهل بنظام الأرصدة وتنويع آليات التقويم النوعي) (OCDE, 2011).

شارك في الورقة البحثية الموسومة ب:إصلاحات

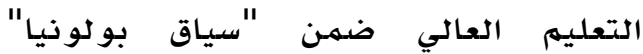
"processus de Bologne" و المستقبل ثلاثة خبراء في الجودة و وتطوير

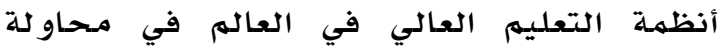
تقييمية للمشروع الأوروبي في التعليه العالي المعروف تحت اسم " مسار بولونيا" و هوعبارة

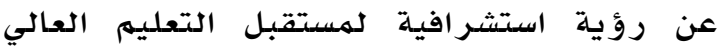
الأوروبي خلال عشر سنوات. ويُفترض وض أن يبدأ

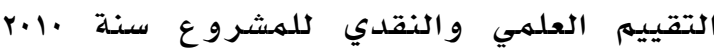
والوقوف على النتائج المحققة و وتشخيص الصعوبات والمعوّةقات التي حالت دون التجسيد العملي لمبادئ الأرضية الأوروبية في التعليهم

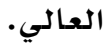

يصف البحث المشروع الأوروبي بأنه المشروع

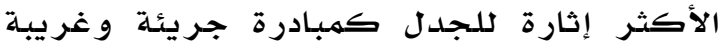

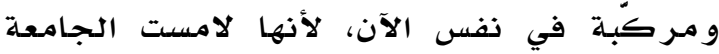

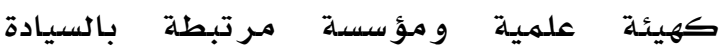
و الهو يلة.

وقد تم" تقسيم البحث إلى ثلاثة أقسام متعلقة بمسـار بو لونيا "processus de bologne" الماضي و الحاضر والمستقبل. ووفيما يتعلق بالتوثيق فتم

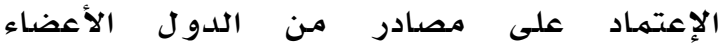
والموقِعة على المسار بالإضافة إلى التقلى التقارير

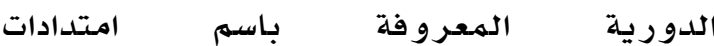
"TENDENCES"

للسجامعة (EUA).

يُرجع البحث تاريخ المشروع إلى سنـة 1999 حين

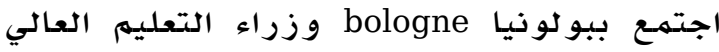

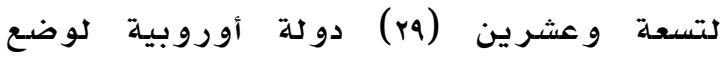

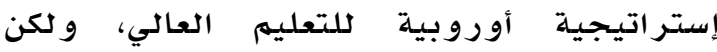
الفكرة و إرهاصاتها تعود لدعوة الوزير الوديه الفرنسي François Allègre للتعليهم العالي فر انسوا أليغري سنة 1991 بعض نظرائه من الاتحاد الأوروبي اليفري

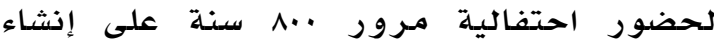

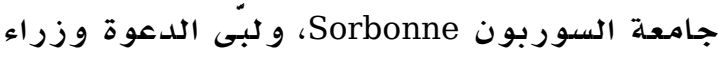

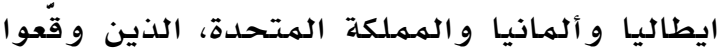

البحوث ذات المصداقية والجودة و الموثوقية

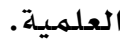

وقد وضعت الدو لتان استراتيجيات سياسية دقيقة و طويلة المدى لتطوير أنظمـة الجامعة وتقريبها مـن العالهيلة من خلال إنشاء أكبـر عدد مهكن مـن الجامعات وتشجيع الإحتر افيةو البحوث التشبـاء التبيقية لتقريب الجامعة من سوق العمل. و بحثت كل

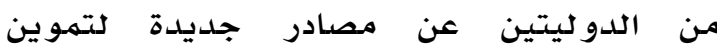

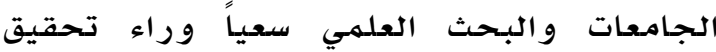
تعليمٍٍ عالٍ مرتفع الجودة.

ويرى الباحث أن التعليم العالي في كل من الصين والهند سوف يتجاوز الحدود الإقليهية

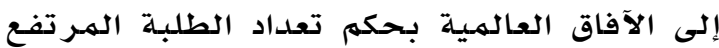
وحجم الإنفاق الجامعي الذي شجـع الأساتذة

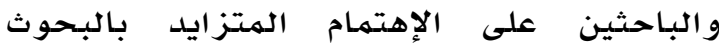
العلميلة والإنفتاح على العالم الخـارجي من خلال تحرير حركة التتقل والإستثمار و والإستعانة بالخبرات الأجنبية. . وقد أرست الصين سياستة جديدة في حقل التعليهم العالي، عرفت باسهم

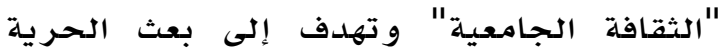
الأكاديمية في البحث وم-حاربة الفساد خاصدة الر شوة و البيروقر اطية مـع وضـع آليات تحفيزية لكلأساتذة منها تحسين الرواتب وظروف فو العمل. الفصل السابع تطرق إلى آليات تفعيل اتفاق

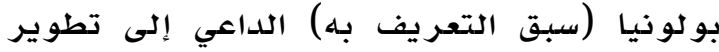
أنظمهة التعليهم العالي في أوروبا والسعي إلى الى إيجاد صيغ جديدة لمطابقة الشهادات ومعادلتها في محاولات أوروبية جادة للوقوف أمام تحديات

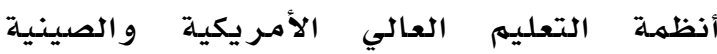
و اليابانية. ودعا أصحاب المقال في النهاية إلى تهائ ضرورة تذليل الصعوبات خاصدة تلك المتعلقة

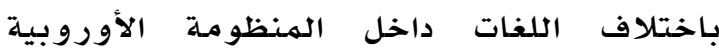
بالإضافة إلى سيطرة القيم التقليدية التي تقف عائقا أمـام التطور بثقلها التاريخي و بتشبثها بالهـرجعيات و الأيديولوجيات. ودعا المقال أيضا

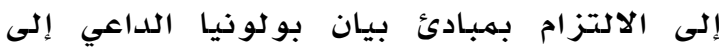

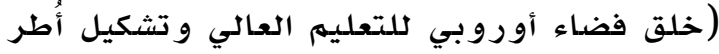

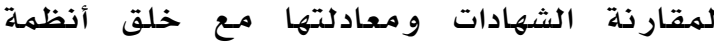
جلديدة في التعليهم العالي في مرحلتي قبل وبعد معلد 
وفي براغ (Prague, 2001) تقرر إضافة ثلاث

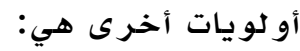

\section{ترقية التكوين مدىى الحياة.}

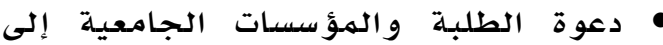

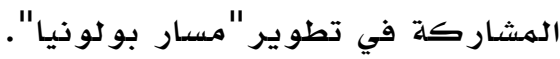

• ترقية الاهتمام بـالفضداء الأوروبي في

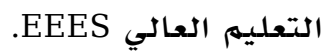

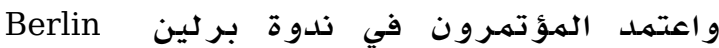
2003، نظام الطور الثالث بالدراسـات ما بعد التدرج، وتشجيع سياسـة "البعدد

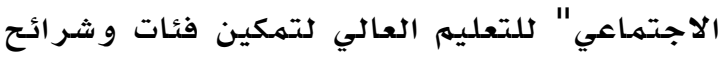

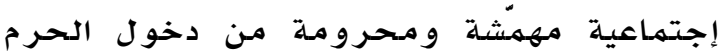

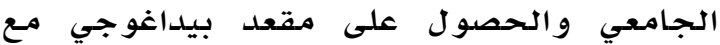

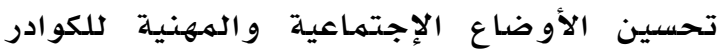
الإدارية و الهيئات التدريسية.

أما في برغن Bergen (النرويج) فقد تمَ تحديد أو لويات جديدة تمثّلت في:

1. دمـج التعليهم العالي والبحث العلمي في سياسـة و احلدة.

r. توسيع نطاق التعاون الدو لي و وتكثيف آليات التبادل المعر في والأكاديمي.

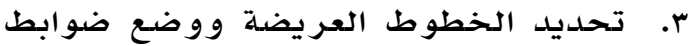

و معايير أوروبية لقياس ضمان الجودة.

و في ندوة لندن Londres 2007 تبنَى الحاضرون المشروع الأوروبي الجديد للتعليم العالي

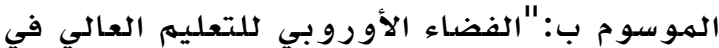

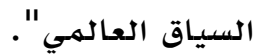

وفي ندوة لوفان Louvain سنة و+.r وهي الندوة

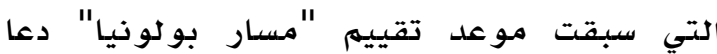
وزراء التعليه العالي الأوروبيين وخبر اء التكوين

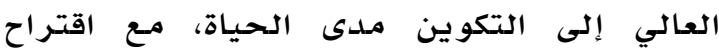
الوسائل البيداغوجية لهذا الضرب من التعليم

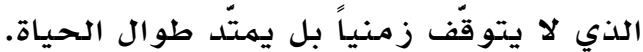

خرج الباحثون في تقييههم "لمسار بولونيا"

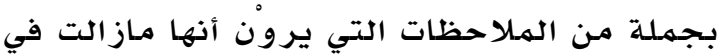
حاجـة للبحث أو التوضيح و إعادة الصياغة و منها:
علي بيان عرف فيما بعد ب: بيان السوربون

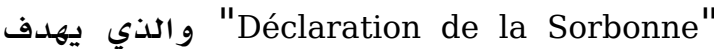

$$
\begin{aligned}
& \text { • خلق فضاء أوروبي للتعليم العالي. } \\
& \text { • التخطيط لوضدع آليات موحدة لتوحيد } \\
& \text { المسـار والأطوار الدر اسية الجـامعية. } \\
& \text { • تسهيل معادلة الشهادات. }
\end{aligned}
$$

• مقترحات لوضـع نظام موحسّ للشهادات.

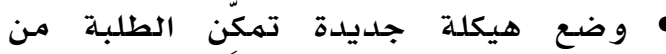

التكوين المتعدد التخصصات.

• تمكين الطلبة من اللغات الحية واستعهمال

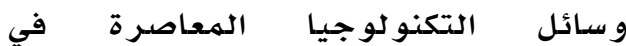

المعلو مات.

• التفكير في إستراتيجية تكوينية وتعليهية

على مدى الحياة.

• تسهيل آليات الوصول للجامعة والحصول

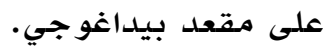

ولم يكن القادة الأوروبيين يتوقعون النجاح

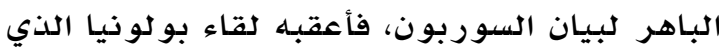

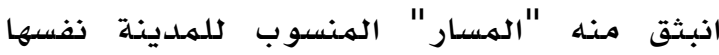

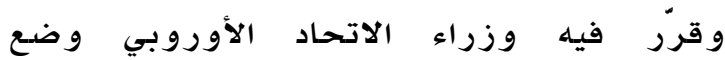

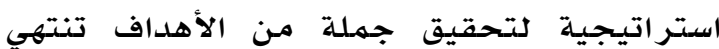
بنهاية سنة .l.l و من هذه الأهداف ما عرف

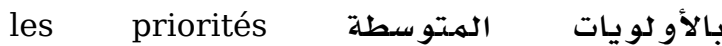
intermédiaires ا. وضع نظام لشهادات يتميّز بالوضوح وسهو لة الهقارنة (القياس الأوروبي). r. اعتماد نظامين أساسيين للتعليه العالي .( $1^{\mathrm{er}}$ cycle et $2^{\mathrm{eme}}$ cycle)

r. تطبيق الأرصدة) ."crédits"

ع. ترقية حركة انتقال واستقبال الطلبة

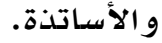

ه. ترقية التعاون الأوروبي في مادة تقويم

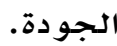

I. تسهيل و توسيع آليات الولوج إلى الجامعة. 
المتعلقة برهانات الإنفتاح و مخحاطره،

و يصـاحب ذلك عجز" في اتخاذ القرارات.

r. مازال المشروع غامضاً بالنسبة للطلبة

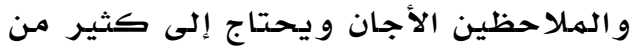

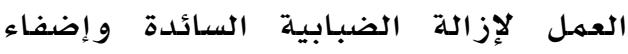
الشفافية الواقعية عليه.

r. غياب النصوص التشريعية الواضحة، حال

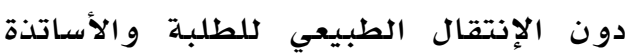

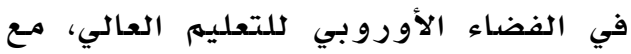

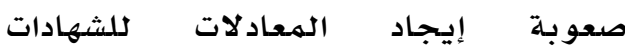
و المؤهلات الجامعية.

ع. بقاء التمـركز حول "الأستاذ" في كل

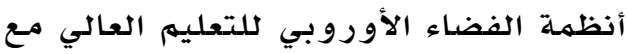

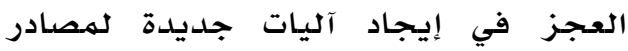
التكو ين و التعليهم.

ه. تحفُظ بعض أسواق العمل ووكالات التشغيل في قبول بعض الشهادات

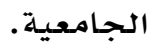

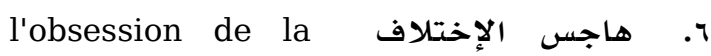
différence منظومـة تعليمية جامعية محلية أوروبية

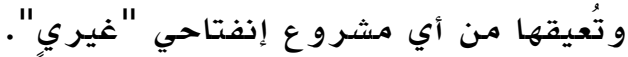

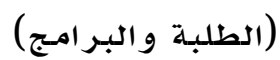

هذه النقائص ق قلَصت من تأثير الهشروع الأوروبي في التعليهم العالي على الهشهد العالمي

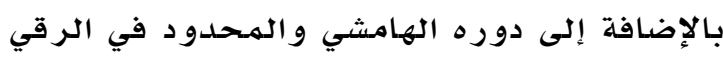
الإجتماعي و التتهمية الإقتصادية.

شغلَت مشكلة القطاع العمومي والقطاع الخاص الفلاسفة والإقتصاديين لترتحل إلى حقل جديد

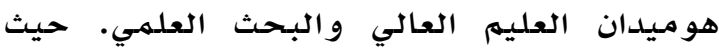

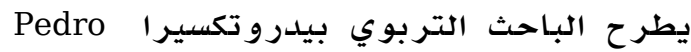
Teixeira و عضوباحث بمعهد البحوث في سياسات التعليم العالي CIPES) في هذه المقاربة إشكالية دخول رأس المـال، في تموين الجامعة والإثراف على على التهاه

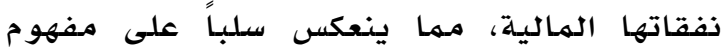

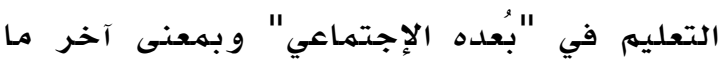

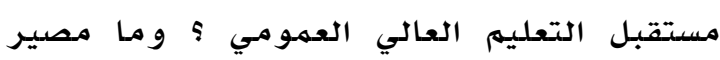

1. إثكالية الشهادات من بنيتها

و أطوارها التعليميلة و الدعوة إلى تلذليل

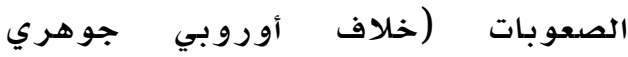
وقاعدي حول معادلة الشهادات).

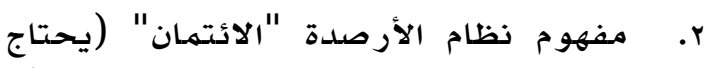

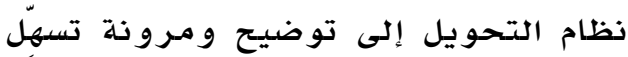
تطبيقه).

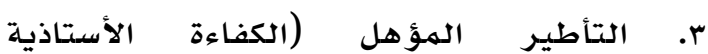
و توحيد أنظمة التقويهم).

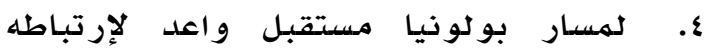

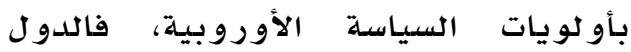

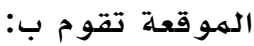

- ترشيد وترقية الإنجازات وتثمينها. - مر اجعة النقائص و الهسارعة في إيجاد حلول لها.

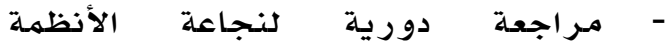

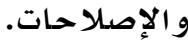

رصد ميزانيات ضخمة لتطوير المناهـج

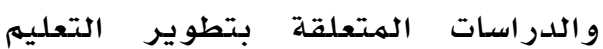
العالي. - الإستعانة بالخبرة الدولية في ميدان

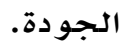

إيلاء الأهمية الفائقة للفجوة الواقعية

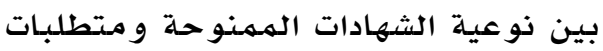

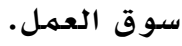

و تسـاءل الباحثون في خاتهـة الدراسة حول

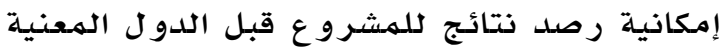

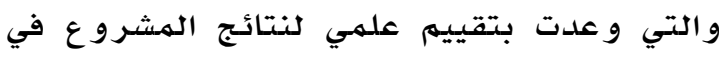
r.l. المسار ( عشر سنوات).

ورغم الإثكالية إلآ أنّ الباحثين قدمّوا رؤيتهم

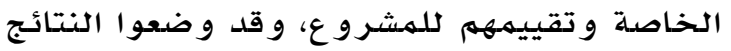
في شكل سينار يوهين:

الأول نعتوه بالمتشائم نظراً للمؤشر ات الآتية: ا. البُطء في التقدم في نسبة إنجاز وتحقيق

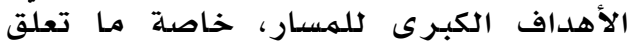

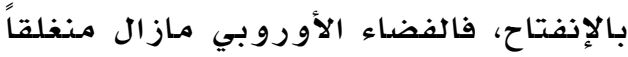
على نفسـ، أسير المناقشات الداخلية 
r. سـارعت بعض الدول إلى إعادة بناء وهيكلة

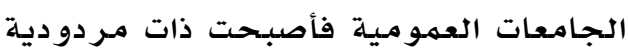

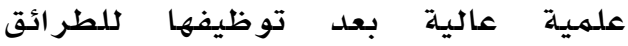
و المناهج و التقنيات الححديثة.

ع. حافظت الكثير من الجامعات العمومية

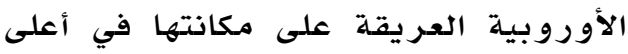
المـر اتب الأكاديمية.

و أمام التزايد العالهـي لعدد الطلبـة والذي انتقل

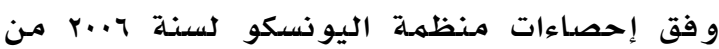

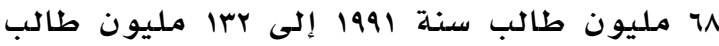

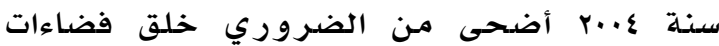
جديدة للتعليم العالي الخاص، وهووجودود طبيعي

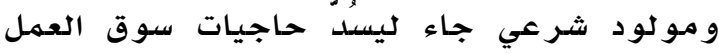
في اليد العاملة المؤهلة. يختم الباحث بتبيان المستقبل الكبير للتعليهم

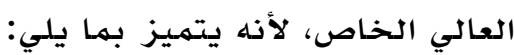
ا. الإستجابة للخطاب الإقتصادي الجديد الهؤسس على المعر فئسة

r. البحث الدائم عن الفعالية و النحـاعة. r. الإستجابة للمستحدثات والمستجدات في عالمسي الإدارة و التجارة. ع. الإستججابة لمتطلبات سوق العمل. ه. تطوير التقنيات البحثية المعاصرة و توظيف المعلو مـاتية.

T. إعتهماد التطبيقات الجديدة في عالهي

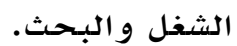

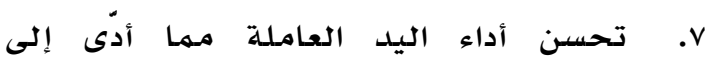
تطوير القدرات الإنتاجية.

و من أهمَّ تحديات مؤسسات التعليهم العالي الخاص ارتفاع رسوم التسجيل، و عدم تفعيل

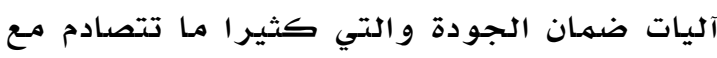

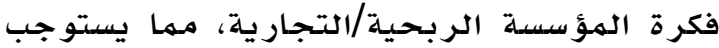
عليها البحث عن طر ائق جديدة لضمان الجودة. و على الرغم من حضورها في المشهد التعليهي

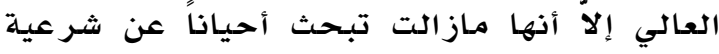

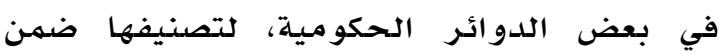

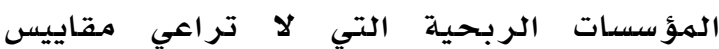

أبناء الطبقات الفقيرة والهـحروومة و الههمشة؟ و في المقابل تعاني الدول الفئاء الفيرة خاصة واصة عجزاً مالياً كبيراً في الإنفاق على الهي التول التعليم العالي، و أصبـح من الضـروري فتتح المجـال أمـام الخواص اصل للإستتثمار في هذا الميلدان.

يذهب الباحث إلى أن التعليم الخاص فكرة قديمة

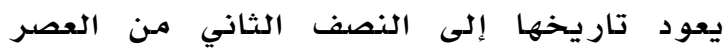

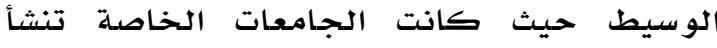

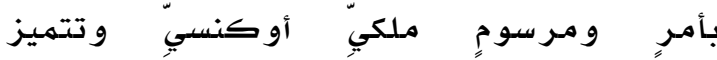
باستقلادية مالية وتنظيمية و هيكلية، و لم تكنية

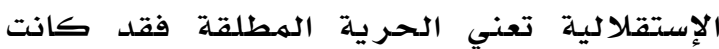
تقدم تقارير للسلطات المدنية أوالدينية.

والإرتباط بين الجامعة والدين علاقة قديمة،

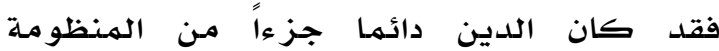
الجامعية باعتبار أن التعليهم العالي التلائيكي

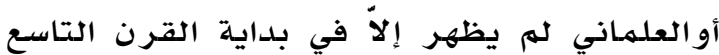
عشر. يستعر ض الكاتب تاريخ نشاة الجامعات في العالم ليؤكد الريادة الأوروبية في النشأة والتأسيس حيث تعود أول الجامعات إلى القرن الحادي التوني

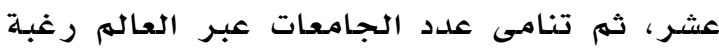
في المعرفة وتوفير الكفاءات واليد العاملة

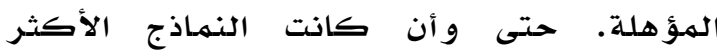
محاكاةً و تقليداً هي الجامعات الأورووبية. ونتيجة للعجز العالمي في تلبية طلبات الإقبال

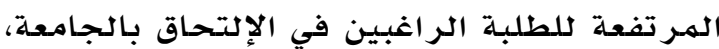

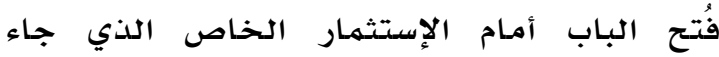

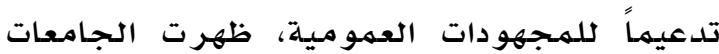
الخاصة في كل القارات و في كل الدولّ و لكن بقو انين و أنظمة مختحلفة

و على الرغم مـ العدد المتززايد للجامعات

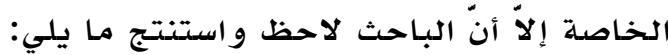
I. مـازال أغلب الطلبة في دول منظمهة OCDE مسجلين في الجامعات العمو مية. r. إلتحاق بعض المؤسسـات الجامعية الدينية

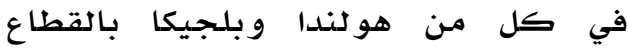

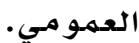


ويدخل التمويل أحيانا في تحديد الفروق بين الهمؤسستين، وتختلف الدول في تحديد نموذج المؤسسـة العامـة و الخاصدة، فالجامعات البريطانية

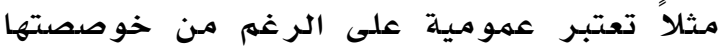
وكذا الأمر في الجـامعات الأسترالية.

OCDE فموماً فإن التعليه العالي في منظمة

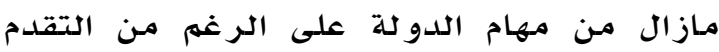

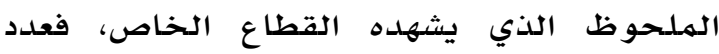
الطلبـة الهسجلين في الجامعات العمومية يتجاوز بكثير الأعداد المسجلة في الجامعات الخاصدة،

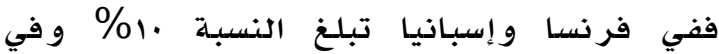

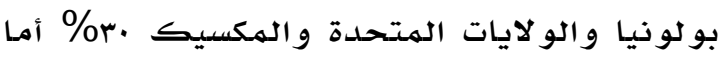

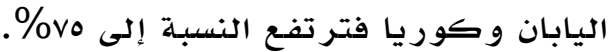
ونتج عن هذه المعطيات، ضعف ملدحوظ في

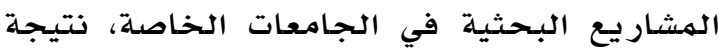

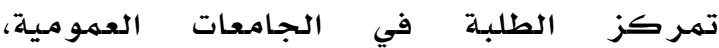

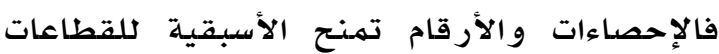

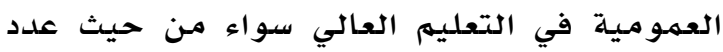

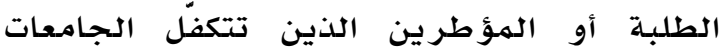

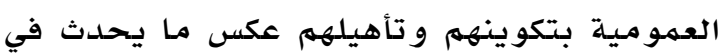

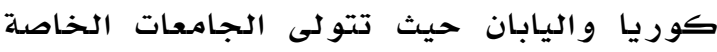
تكوين وتأهيل الهيئة التدريسية. يرى البـاحث أن القضية المالية أو التمويل

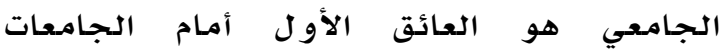
العموميـة، و في مقارنة بسيطة بين مجهمو عة من الجامعات يمكن مـلاحظة الفروق التمويلية التي

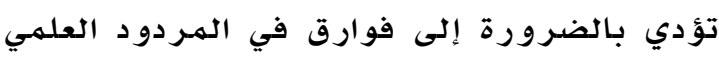
والبحث الأكاديهي عالي الجودة، فجامعة ليال Yale University

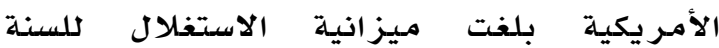

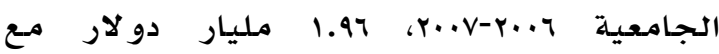

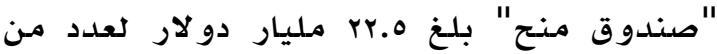

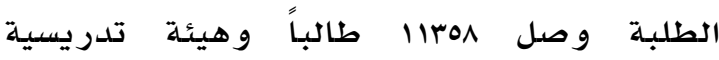
تجاوزت ع^سم أستاذاً.

في حين بلغت ميزانية جامعة باركلي Berkeley

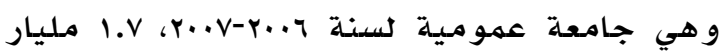

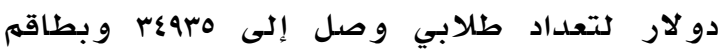
تدريسي دائم بلغ دو.r أستاذاً.
و معايير الجودة، بالإضافة إلى غياب الهيكل القانو ني و التشر يعي.

Stéphan يعد الباحث ستيفان فانسان لانكرين Vincent-Lancrin

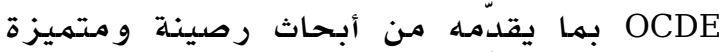
في حقل التربية والتي تُعتمد في حالات كثيرة كأرضية للتشريع أومشاريع تنتظر التجسيد

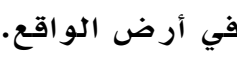

قدّم في هذا البحث مقاربة تطبيقية مدعمّة

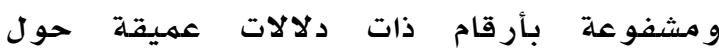

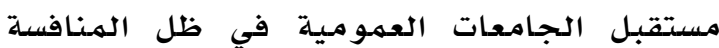
الشديدة للمؤسسات الجامعية الخاصدة.

قبل إجراء الهقارنة بيّن عدد الطلبـة الهنتسبين

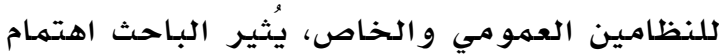

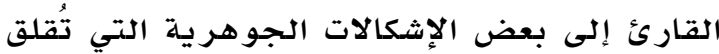

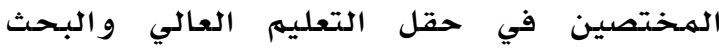

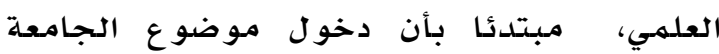
و الخدمات التعليمية في الإنفاق العام للتجارة

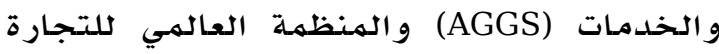
و "سلعنة" التعليهم العالي بات أمراً مقلقاً (OMC) في أوساط المـختصين حول علاقة التعليه العالي

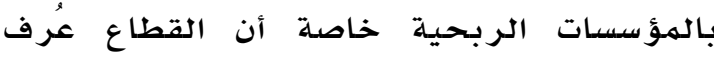
بانتمائه إلى القطاع العام. يُبرز الباحث منهج بحثه، فيوضتح أنه يعتمدد على المقارنة كآلية لقياس مدى النجاعة و الفاعلية

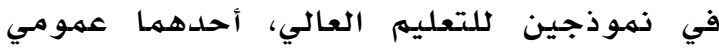

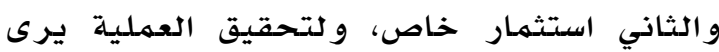
الباحث ضرورة ضبط المفاهيم والمصطلمات

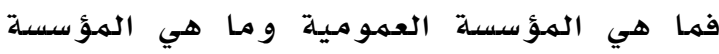
الخخاصة؟

المؤسسة العمـومية في رأيه كل مؤسسة مسيّرة مباشرة من سلطة أو هيئة للتعليهم العمومي

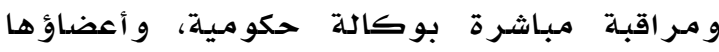
معينون من السلطات العمومية أو منتخبون. في حين أن المؤسسة الخاصدة مسيّرِّرة ومـراقبـة

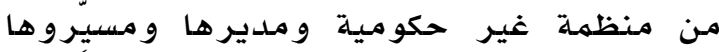
ليسوا معينين من السلطات العمومية. 
ومنها ما يتعلق بالعامل البشري سواء الطواقم الإدارية أو الهيئات التدريسية.

يبدأ الباحث دراسته التحليلية بمقولة تلدعو إلى

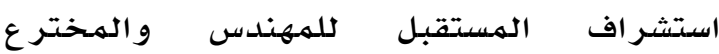

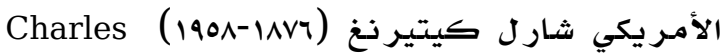
F. Kettering التي أريد أن أكمل فيها بقية حياتي) وفي الهاتيا

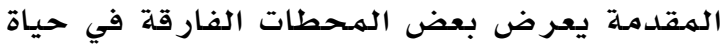
البشرية منها ظهور الأجسام الغريبة (ovni) لأول

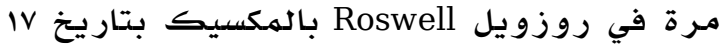

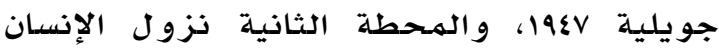
لأول مرة على القمر بتاريخ ال جويلية 1979. إن هذه الأحداث غيَرت الحياة البشرية ودفعت

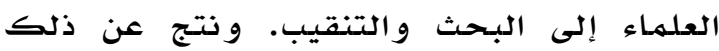
ثورات تقنية وطبية كبيرة حولت لوناء مسار الإنسانية، فأصبح الثابت لا مكانة له فئية في العالم

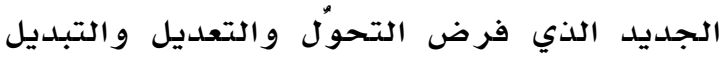
كآليات حداثية يجب أن تصاحب كل القطاعات. وهذا ما دفع بالعلماء إلى استشراف المستقبل

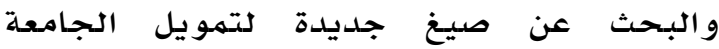
و المؤسسات البحثية العالية، خاصة في ظل تزايد عدد الطلبة والإقبال الكبير على التعليم لهيه الجمامعي.

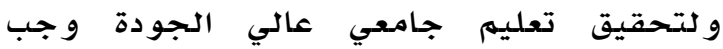
تجديد الهياكل بمختلف أشكالها سواء ماء ما تعلق بالتجهيزات و الوسائل التربو يـة أوما تعلق بالهئية التدريسيـة المؤهلة.

إن التغيرات الجوهرية والعميقة في تركيبة السكان وجدلية شيخوخة المجتهمع (يرى مكتب التهي الإحصاء الأمريكي US census bureau غاية r.o. في بعض دول من منظمة OCDE منها إسبانيا

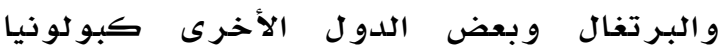
بلغاريا وجمهورية التشيك وقوند يتجاوز أغلبية التهرية

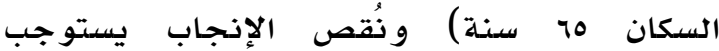

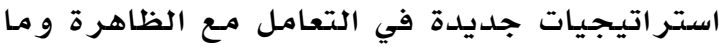

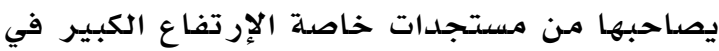

وجامعة فينًا بالنمسا وهي من أحسن الجامعات

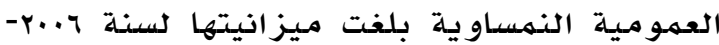
ro\&، r..V Vr....

وبالمقارنة البسيطة يلاحظ الباحث أن الموارد

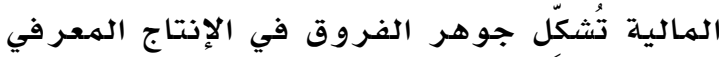

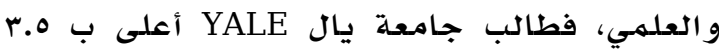

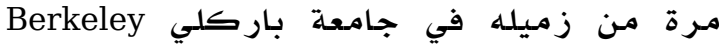

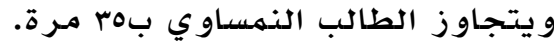

يشكل القسم المالي محور النوعية والنجاعة في

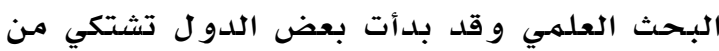

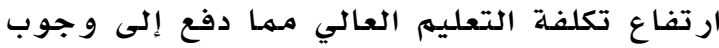
البحث عن آليات جديدة للتهو يل، فقد موّلت دول منظمة 0CDE، \% \% من المشاريع البحثية في r... 7 aن

وبارتفاع تكاليف ونفقات التعليم العالي يدعو

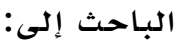

- البحث عن موارد مالية جديدة لتقديم

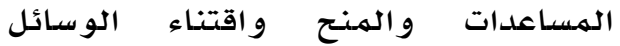

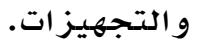

- تشجيع إنثاء مؤسسات للتعليه العالي

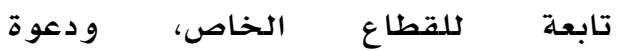
المستثمرين إلى اعتبار قطاع التعليم

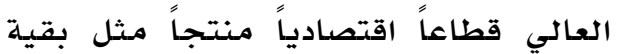
القطاعات الصناعية و التجارية الأخرى. وضع تشريعات و ولوائح قانونية لحماية الاستثمار في قطاع التعليهم العالي.

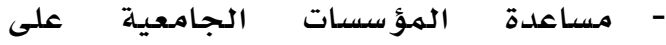
الإستقلالية خاصدة فيما يتعلق بالتمويل

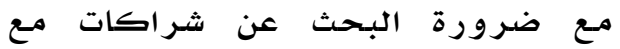
القطاعات الصناعية.

\section{الفصل العاشر}

يفتتح جميل سالهي من البنك العالهي بحثثه

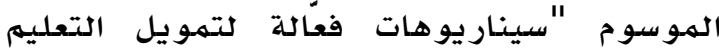

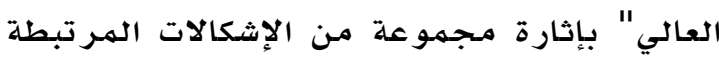

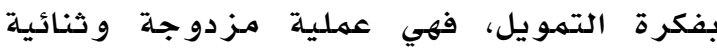
منها ما يتعلق بالوسائل المادية والتجهيزات 
ء. تقديم صكولك للتعليه، مُوزّعة على فترات

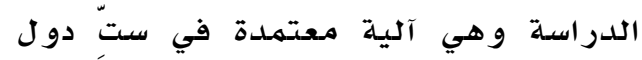

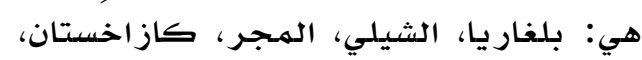

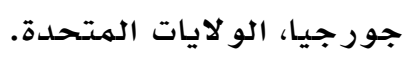

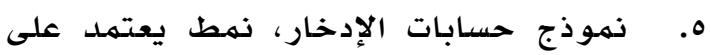

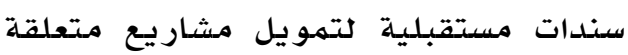

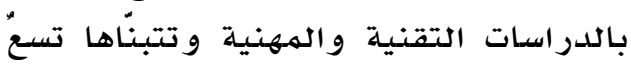
دول هي: بلديكا - بندا- ماليزيا

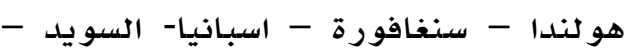

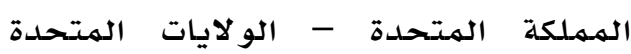

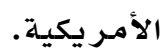
يقترح الباحث في خلاصدة دراسته مايلي: ضرورة إعادة هيكلة الجامعة من الناحية

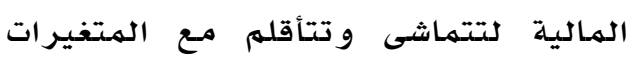

$$
\text { و التحو لات العالمية. }
$$

^. إعادة تشكيل الفضاء الجامعي وفق معايير

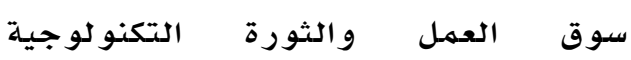
و المعلو مـاتية وقيهم ضمـان الجودة. 9 9. تنويع وسائل التمويل وضرورة التخلص التحس

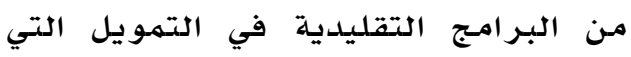
تُعيق الإنتاجية و الرو البراج التقليدية التنافسية.

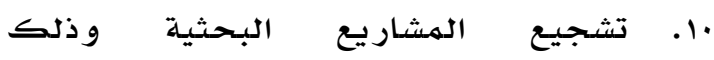
بالشراكة الفعالة بين القطاعين العهمومي

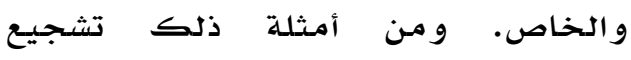
مشاريع الطالب/الهنتج أوالطالب المشروع المناله

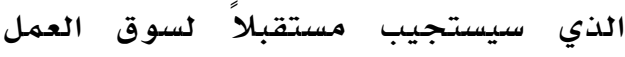

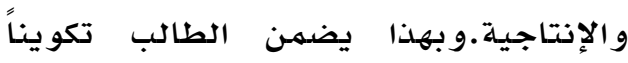
و منصب عمل، ومن ذلك اله الهشروع الذي الذي

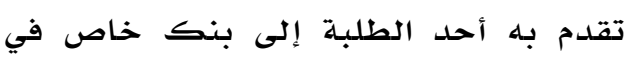

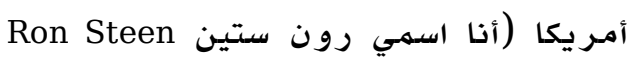

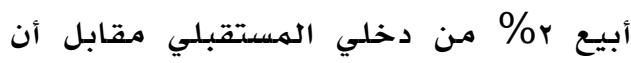
التحق بكلية علمية) (OCDE, 2011).

يذهب الخبير الدولي في البحث عن ضدمان

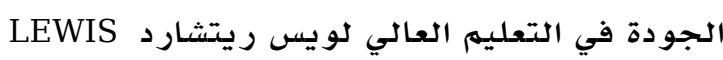
RICHARD

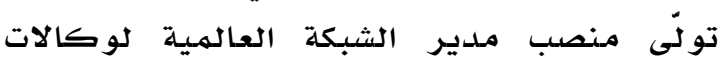

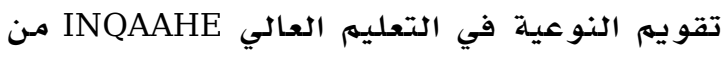

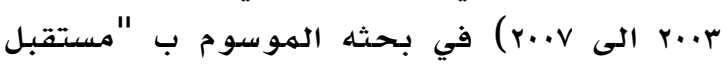

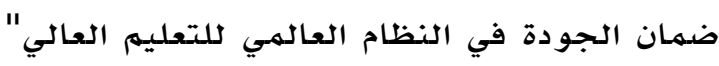

النهموالسكاني في إفريقيا و وباكستان و الهند

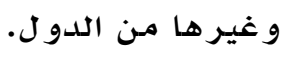

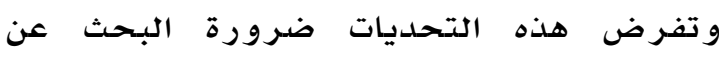
سياسات جديدة لتمويل الجامعات و الوقوف أمام

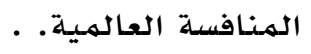

وقد اتخذت بعض الدول إجراءات تقشفية منها

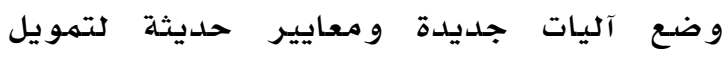

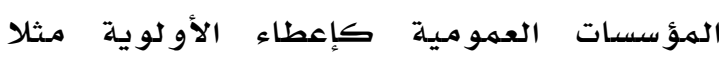

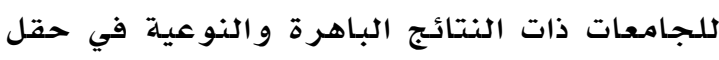

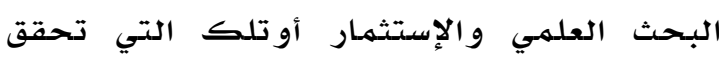

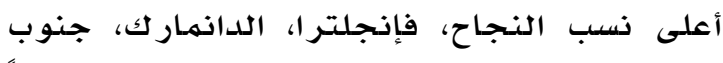

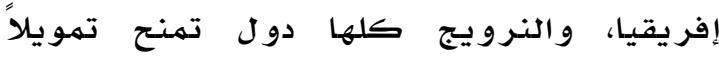

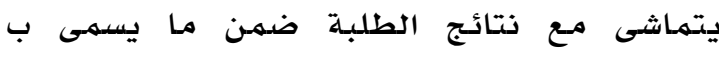

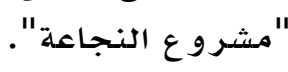

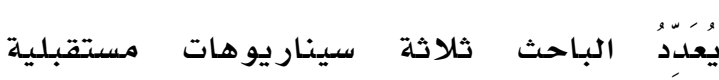

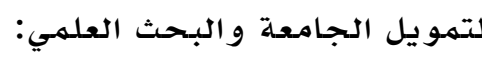

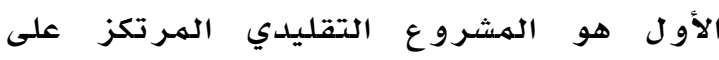

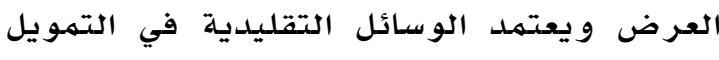
خاصة من السلطات العمومية التي تسعى لإتاحة

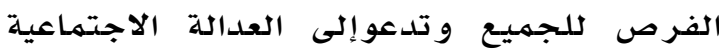
و تمكين الجميع من الدر اسـات الجـامعية.

الثاني ويتمثل في النظام التقليدي المعتمد على المدام الماهد

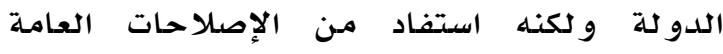

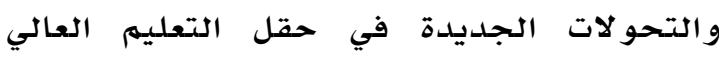
بظهور الهؤسسـات الخاصدة، فيحاول الجهـع بين القديم و الحمديث. النهط الثالث هو السيناريو الهرتكز على الطلب

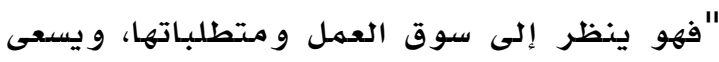

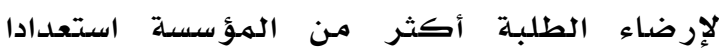

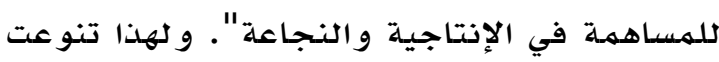

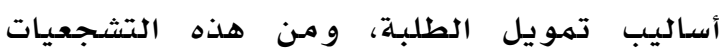
مايلي:

ا. تقديم منح و مساعدات للطلبة غير قابلة للتعويض.

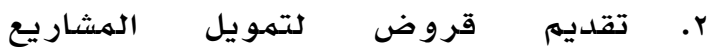
و الدر اسات الجامعية.

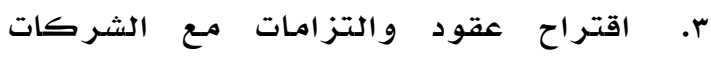
الخاصدة لتمويل الدراسـات الجامعيلة. 
r. تقديم الدعم والخبرة للدول الر اغبة في إنشاء وكالات لضمان الجودة.

ع. تسهيل التواصل بين الهيئات الهعتمدة في تطبيق ضمان الجودة.

ه. مساعدة الأعضاء على تحديد وتوحيد

$$
\text { معايير التجودة. - معاه }
$$

7. تطوير أساليب ضهمان الجودة للمؤسسات

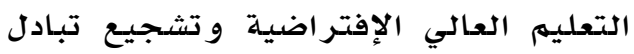

المعار ف و البحوث مـع مختلف الوكالات.

V. السعي لتسهيل الإعتر اف الدو لي بالشهادات

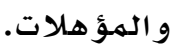

^. تسهيل آليات انتقال الطلبـة بين الدول مـع

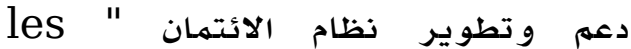

."crédits

9. نقد وتحليل وتقييم الدراسـات و البحوث

$$
\text { في حقل ضمان الجودة. }
$$

•1. مساعدة دعم إجراءات ضمان الجودة في الجامعات و مؤسسات التعليم العالي.

و ولترقية وضمان مستقبل الجودة، يرى الباحث

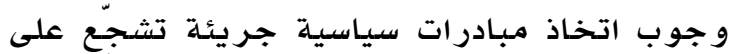

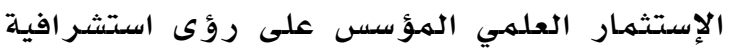

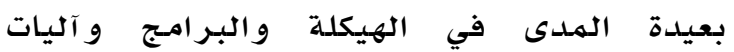

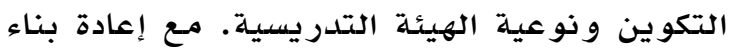

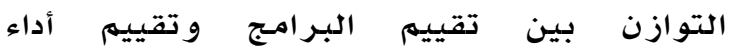
المؤسسات التعليمية. والبحث العميق في في أهمٍ المعارف التي تقدم للطلبة وبمعنى آخر ما هي مضامين البرامج التعليمية؟ التي يشترط فئر فيها

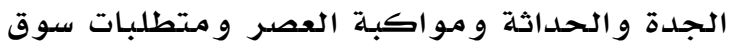

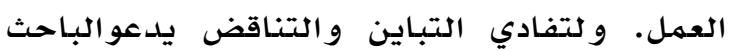
إلى الالتز ام بميثاق دبلن "descriptifs dedublin"

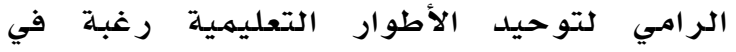

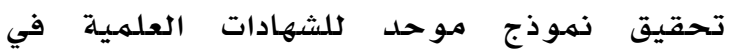

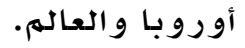

يدعو الباحث في نهاية دراسته إلى أن جميع

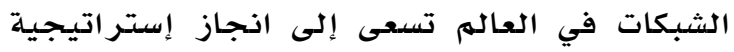

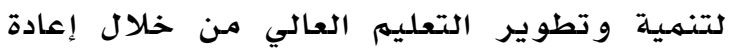

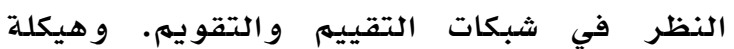

إلى العودة إلى الإشكالية الإبيستيمولوجية

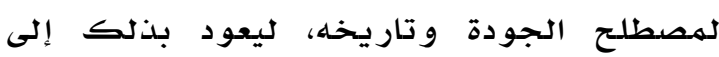
الأصول و الجذور والإرهاصـات الأولية لنشأة

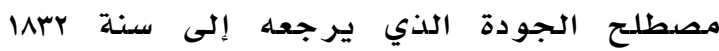

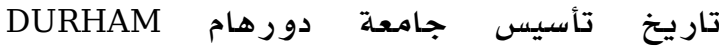
الإنجليزية (جامعة دورهام ثالث أقدم جامعة في

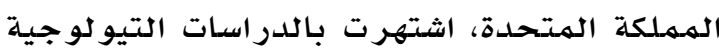

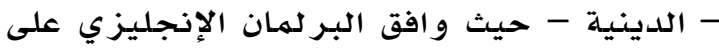

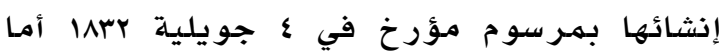

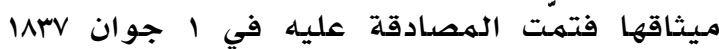
من طرف غييوم الرابع GUILLAUME IV) و هي جي ثالث جامعة في المملكة المتحدلة بعد أكسفورد المرد و كامبريدج، ومـع نشأتها بدأت عمليات الهقارنة حول نجاعة التدريس الجامعي و والتفضيل بين الجامعات من حيث التكوين و ونوعية المكوّنين

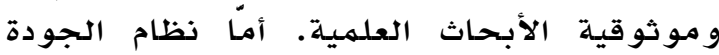

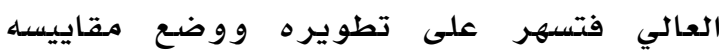
العالميلة منظمات أكاديمية ذات صيت دو لي منهها، inqaahe (International (INQAAHE) شبكة دوية Network For Quality Assurance Agencies In Higher Education)

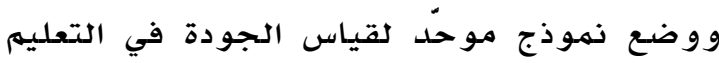
العالي ووهي:

الشبكة الدولية لوكالات ضونمان الجودة في

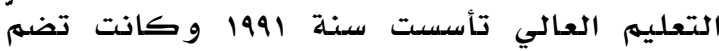
ثمانية أعضاء، ليتجاوز عدد أعضائها اليوم

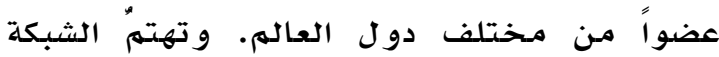
بتطوير أنظمة الجودة في التعليم العالي

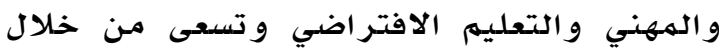

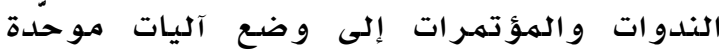
لإدارة الجودة والتقويه. تعقد الشبكة مؤتمرات

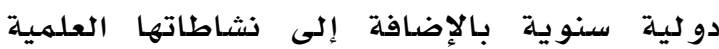
المتمثلة في الإصدارات الأكاديميلة من مجلاتلات و كتب ودر اسـات ميدانية، و مـن أهم مبادئها:

ا. ترقية وتشجيع البحوث المهمارسات الر ائدة لتحسين أنظمة الجودة في التعليم

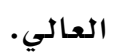

Y. تسهيل البحث في مسمارسة إدارة الجودة و الكفاءة في مجال التعليم العالي. 


\section{ظهور نزعات وطنية ضيقة النظرة و عنصرية في أحيان أخرى، تتعصب للغة

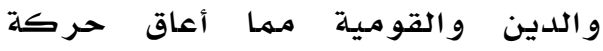

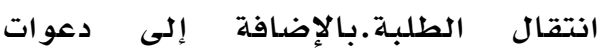

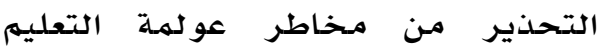

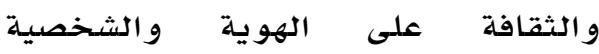 الو طنية.}

\section{نتائج الدراسـة}

\section{أ- في مجال الديموغر افيا:}

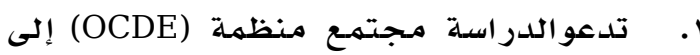
ضرورة تشبيب الهؤطرين و إتباع سياسـات

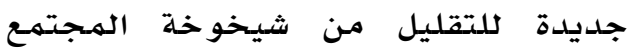
و ذلك بتشجيـ الإنجاب. r. ضرورة إتباع مناهـج واستر اتيجيات جديدة

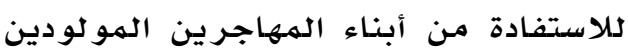

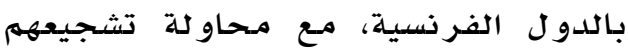
على التكيف مـع الثقافة الفرنسية، تفاديا

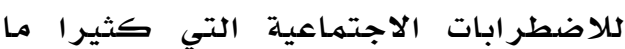
تصاحب شعور هم بالتهميش و الاغتر اب. r. تقليص الفجوة بين الجنسين في التعليم

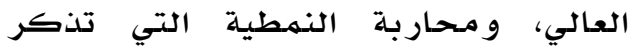

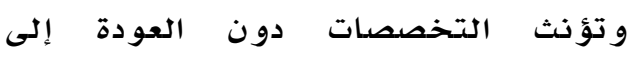

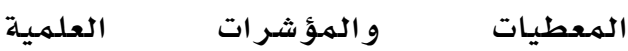

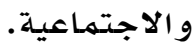

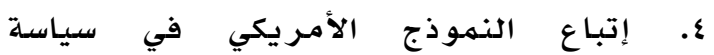
المواطنة التي جعلت من الفئات المهاجرة، المهردئ

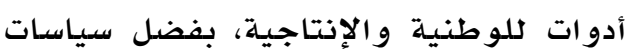

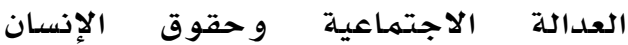

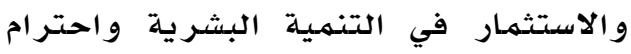
الخصو صيات الثقافيـة و العقائدية.

0. تكييف هياكل التعليه العالي و مناهجه بها

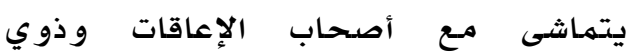
الاحتياجات الخاصة و مححاربة كل كل مظاهر التمييز و الإقصاء و التهميث.

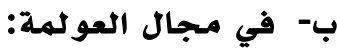

ا. فتح وإنشاء مـراكز البحوث والدراسات والجامعات في كل دواءتاء مراسر العالم وتلدوعيم
المؤسسـات في البناءات والبراتج

مجمل القول و وصفوته حول هذه الدراسلة في

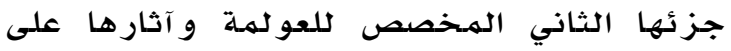
التعليهم العالي، تأتي ملخصلة التهل على النحوالتالي:

تأقلمر جميـع أنظمة التعليهم العالي

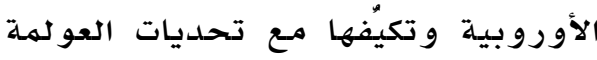
و إفر ازاتها الهـعر فية و الإنتاجية.

انفتاح منظومة التعليهم العالي الأوروبية

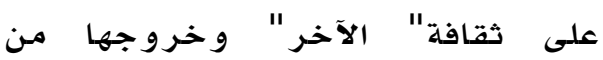

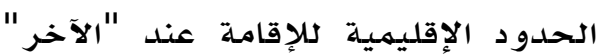
استثمار ا و تعليما و بحثثا. بداية تحول التعليم العالي إلى بضاعة تسلهم فيها شهادة ضهمان للجودة. تقلص نسبـة الإنفاق على التعليهم العالي من قبل الدول وفتح المجال أمام المستثمـر ين الخواص.

بفضل الإمدادات المالية للاستثمار، تم تجديد الوسائل التعليمية من هياكل و بر امـج واستراتيجيات و تشجيع البحوث

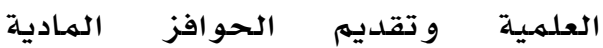
كلأسـاتذة و البـاحثين.

تشجيع الهجرة المؤهلة من الدول

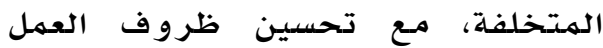

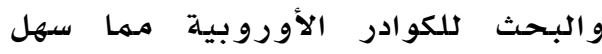
عملية الهجرة الداخلية. وجوب البحث عن آليات جديدة لتمويل الجامعات و البحوث البحوث العلمية.

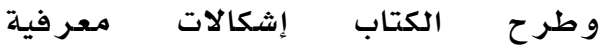
واجتماعية نتيجة للعولهمة في التعليم العالي منها: ظهور اللاتكافؤ الاجتهـاعي و الطبقية في

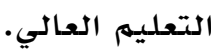
ارتفاع تكاليف التعليهم الجامعي في المؤسسات الخاصـة. 


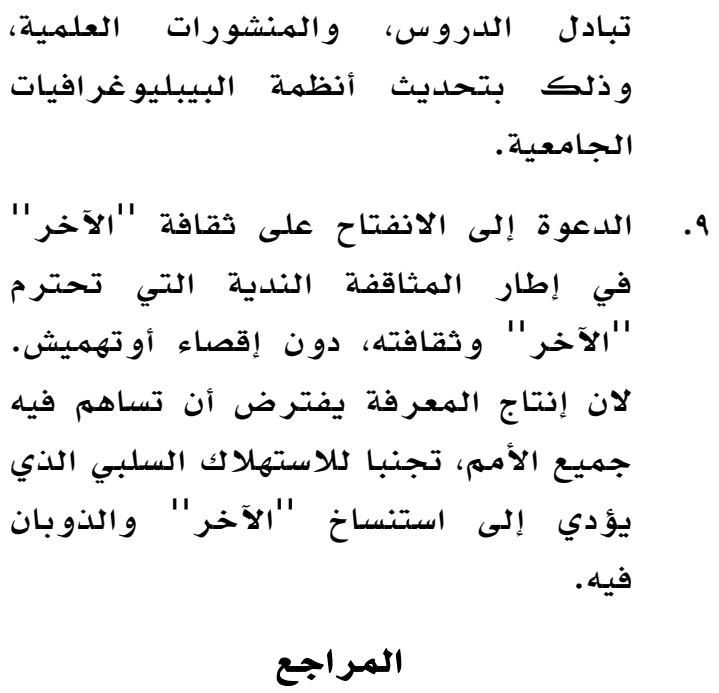

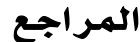

OCDE, (2008). L'enseignement supérieur à l'horizon 2030, volume 1, Démographie, Editions OCDE, Paris, 118-242.

OCDE, 2011, L'enseignement supérieur à l'horizon 2030, volume 2 mondialisation, Editions OCDE, Paris, 3-43-132-137-147-176-188-206205-246-274-370-380.

Banque M. (2003). Construire les sociétés des savoir; nouveaux défis pour l'enseignement supérieur, les presses de l'université de Laval, CANADA, $\mathrm{p}, 37$.

Charlier, J. É., Croche S. et LECLERCQ B. (2012). Contrôler la qualité dans l'enseignement supérieur, Edition académia, éducation enseignement, Paris,p, 224.

Darbellay F. \& Paulsen T. (2011). Au miroir des disciplines: réflexions sur les pratiques d'enseignement et de recherches -inter-et transdisciplinaires, Peter Lang SA, Berne, p,97.

globalisation, quels enjeux pour les universités? Actes $d u$ colloque de Laval,18 au 21 septembre 2002.

OCDE, (1999). Les établissements de l'enseignement supérieur face aux besoins régionaux, édition OCDE, Paris.

OCDE, (2007) L'enseignement supérieur et régions concurrence mondiale engagement local, édition OCDE, Paris.

OCDE, (2004). L'enseignement supérieur, internationalisation et commerce, édition OCDE, Paris.

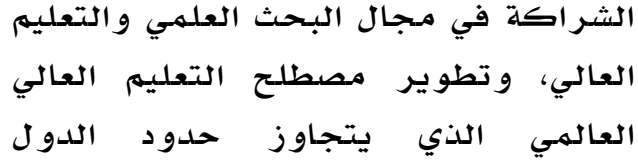


OCDE, (2005). Le cyberformation dans

l'enseignement supérieur état des lieux, édition OCDE, Paris.

Perellon, F. (2003). La qualité dans

l'enseignement supérieur, presses polytechnique et l'universitaires romandes, Lausanne, Suisse.

Granier C. (2009). La démarche qualité dans la recherche publique et l'enseignement supérieur, Edition QUAC, Paris, p, 384.

Hélène B. (2012). Garantie de la qualité dans l'enseignement supérieur: sélection de documents en langue française, centre de ressources et d'ingénierie documentaires, paris.

OCDE, (2004). Qualité et reconnaissance des diplômes de l'enseignement supérieure, un défi international, édition de l'OCDE, Paris.

OCDE, (2008). l'enseignement supérieur transnational un levier pour le développement, édition OCDE, Paris. 